\title{
Extraction and Enzymatic Modification of Functional Lipids from Soybean Oil Deodorizer Distillate
}

\author{
Carlos F. Torres, Guzmán Torrelo and Guillermo Reglero \\ Departamento de Producción y Caracterización de Nuevos Alimentos \\ Instituto de Investigación en Ciencias de la Alimentación (CIAL), CSIC-UAM \\ Madrid \\ Spain
}

\section{Introduction}

Crude vegetable oils contain triacylglycerols as major component and various minor components such as diacylglycerols, monoacylglycerols, free fatty acids, phospholipids, tocopherols, sterols, squalene, color pigments, waxes, aldehydes, ketones, triterpene alcohols and metals that may affect the quality of the final product. The minor components are removed partially or entirely by either physical or chemical refining in order to make the vegetable oils suitable for human consumption. Deodorization is the last major processing step in the refining of edible oils. It has the responsibility for removing both the undesirable ingredients occurring in natural fats and oils and those which may be imparted by prior unit processes such as caustic refining, bleaching, hydrogenation, or even storage conditions. It is this unit process that finally establishes the oil characteristics of "flavor and odor," which are those most readily recognized by the consumer (Gavin, 1978).

Deodorizer distillate is a by-product of deodorization, which is the last major step in vegetable oil refining process. It is a complex mixture of free fatty acids, mono-, di- and triacyglycerols, sterols and their esters, tocopherols, hydrocarbons, pesticides, and breakdown products of fatty acids, aldehydes, ketones and acylglycerol species (Ramamurthi \& McCurdy, 1993). Deodorizer distillate is an excellent source of valuable compounds such as phytosterols, tocopherols and squalene, which can be recovered and further used as food additives, in pharmaceutical industry and cosmetics. Their commercial value however, is mainly dependent on their tocopherol content (Fernandes \& Cabral, 2007). Although in recent years, efforts from industry resulted in a significant number of reports, describing better and improved methods for phytosterol recovery and purification. Such surge is closely related to growing market for phytosterols, particularly given the widespread dissemination of functional foods (Fernandes \& Cabral, 2007).

Numerous procedures have been described to isolate bioactive compounds from soybean oil deodorizer distillate to improve the value and the quality of this by-product. All these procedures can be grouped in three generic categories: crystallization and precipitation, chemical and enzymatic modification, and extraction and fractionation.

One important bioactive compound concentrated in intermediate byproducts and waste streams during the refining of soybean oil is squalene. Recently, steroidal hydrocarbons and 
squalene in soybean oil deodorizer distillate have been isolated and identified. Separation, purification, and chemical characterization of hydrocarbons fraction in soybean oil deodorizer distillate will help researchers finding a better utilization of these byproduct (Gunawan et al., 2008b, Kasim et al., 2009). Both squalene and steroidal hydrocarbons have been purified from soybean oil deodorizer distillate by means of modified soxhlet extractions with hexane to obtain two main fractions: one fraction rich in fatty acid steryl esters and squalene and a second fraction rich in tocopherols, free phytosterols, free fatty acids (FFAs) and acylglycerols. Then hydrocarbons are isolated via silica gel column chromatography. Similarly, other procedures described in the literature for isolation of sterols and tocopherols in soybean oil deodorizer distillate are based on the utilization of organic solvents (Lin et al., 2004).

Recently greener technologies for isolation, purification and fractionation of bioactive compounds from soybean oil deodorizer distillate (SODD) have been developed. These methodologies can work in combination or independently to improve the fractionation of soybean oil deodorizer distillate. Hence, lipase-catalyzed methyl or ethyl esterification of SODD to transform free fatty acids into their corresponding fatty acid methyl or ethyl esters coupled to molecular distillation and/or supercritical fluid extraction has been described as a strategy to improve the separation between tocopherols, sterols and free fatty acids (Torres et al., 2009). Alternatively, enzymatic esterification of the sterols with the fatty acids already present in the deodorizer sludge makes the separation of tocopherols and sterols simpler using short-path distillation or supercritical fluid extraction (Shimada et al., 2000). However, short path distillation (Ito et al., 2006), supercritical fluid extraction (Chang et al., 2000), and enzymatic modifications (Torres et al., 2007) have been also utilized independently on soybean oil deodorizer distillate. Therefore, these three technologies will be analyzed and discussed on the present chapter to evaluate the feasibility of these procedures for the valorization of side-stream products obtained during refining of soybean oil.

In addition, oxidation of sterols during refining steps such as heating, degumming, neutralization, bleaching, and deodorization, and during storage and handling should be also considered (Verleyen et al., 2002b). However, limited information is available on the levels of sterols in the by-product fractions collected from chemical and physical refining processes (Verleyen et al., 2001c) and the biological effects of phytosterol oxidation products on animal and human health need more investigation, as feed quality is crucial for animal health and welfare, and ultimately human health. It has been reported that the formation of sterol oxidation products is affected not only by the chemical nature of the sterols but also by their quantity (Dutta et al., 2006). Positive correlations between total sterols and total phytosterol oxidation products in the by-products collected from refining processes have been found (Ubhayasekera \& Dutta, 2009). Therefore, other aspects concerning soybean oil deodorizer distillate such as nonfood applications, direct consumption, and oxidative quality will be also analyzed and discussed in the present chapter.

\section{Soybean oil deodorizer distillate production and characterization}

The vegetable oils correspond about $70 \%$ of demand of natural oils and fatty acids consumed in the world. The soybean oil corresponds from 20 to $30 \%$ of the vegetable oils world market (Bockisch, 1998) and its production involves several steps that are necessary to render the soybean oil suitable for human consumption. These production steps have been broadly characterized as 1) soybean preparation, 2) oil extraction, and 3) oil refining. 
Soybean preparation generally includes the steps of cleaning, drying, cracking, and dehulling.

Oil extraction basically consists of separating the oil from the remainder of the soybean, known as soybean meal. The great majority of commercial soybean extraction processes use a solvent to separate the oil from the meal. In the solvent extraction process, the beans are flaked to provide a large surface area. A solvent, commonly hexane, is then pumped through the soybean flakes, dissolving the oil in the hexane. The hexane is then separated from the oil and recycled.

The crude oil resulting from the extraction process must then be subjected to additional treatments, collectively called "refining", to remove various materials in order for the oil to be suitable for consumption. These materials include hydratable and non-hydratable phospholipids, free fatty acids, and various color and flavor components.

Crude soybean oil contains phosphorous compounds called hydratable phospholipids, and small amounts of calcium and magnesium that complex with a portion of the phospholipids to form non-hydratable phospholipids. Hydratable phospholipids are normally removed by a process known as "degumming", in which the oil is agitated or otherwise intimately combined with water to precipitate gums from the oil. The gums are then removed by centrifugation.

These precipitated gums can be used as a feed additive, or evaporated to remove moisture, the end product is called lecithin. Lecithin has various end uses such as food emulsifier. The degummed oil is dried under vacuum to remove any water. Removal of non-hydratable phospholipids is considerably more difficult and expensive, requiring further chemical treatment, typically chemical refining, to break the chemical bonds between the calcium or magnesium ions and the phospholipids, followed with extensive bleaching of the oil.

In most processes, free fatty acids are then removed from the oil by a process known as caustic refining, also called chemical or alkali refining, in which the oil is mixed with a caustic material, such as sodium or potassium hydroxide, which undergoes a saponification reaction with the acids, forming soaps that are then removed by centrifugation. In this case, the non-hydratable phosphotide are removed along with the free fatty acids. In addition, a significant quantity of the oil is captured by the soaps, adversely affecting oil yield.

Free fatty acid removal by a process known as physical refining has been used for oils that are low in non-hydratable phospholipids, such as lauric oils, particularly palm oil. In physical refining, the oil is vacuum distilled at high temperatures, e.g., from about $230{ }^{\circ} \mathrm{C}$ to about $260{ }^{\circ} \mathrm{C}$ to separate more volatile components from the oil. This process is used to remove various flavor components, and will also remove free fatty acids. However, the process has not been viable for removing free fatty acids from oils such as soybean oil, which contains higher levels of non-hydratable phospholipids (more than $20 \mathrm{ppm}$ based of phosphorous content). The high temperatures required for physical refining tend to break down the non-hydratable phospholipids that are present in the soybean oil, producing chemical compounds that cause an unacceptable flavor and color.

Conventional refining processes also involve some bleaching of the soybean oil to remove color pigments (i. e., carotenoids, chlorophyll) that adversely affect the color of the oil. Bleaching process employs the use of adsorbents such as acid-activated clays.

Finally, deodorization is the last process step used to improve the taste, odor, color and stability of the oil by means of removing undesirable substances. The goal of deodorization is to obtain a final product, finished oil that has a bland flavor, a maximum FFA content of $0.05 \%$ and a zero peroxide value. All commercial deodorization, whether in continuous, 
semicontinuous or batch units, is essentially a form of physical distilling by steam, in which the oil is subjected to high temperatures $\left(210^{\circ} \mathrm{C}-280^{\circ} \mathrm{C}\right)$ under a high vacuum $(1-6 \mathrm{~mm}$ $\mathrm{Hg}$ ) for a short period of time, which is sufficient to remove FFA and other volatile flavorcausing compounds. During the process, peroxide decomposition products, color bodies and their decomposition products are eliminated and the content of sterols, sterol esters and tocopherols is also reduced.

The modern commercial deodorizers are equipped with a packed column that has three sections: vapour scrubbing section, stripping section and heat bleaching section.

Bleached oil is pre-heated by outgoing deodorized oil and sprayed into the Deaerator where dissolved air and moisture are reduced to a minimum. The oil is then heated to full temperature by hot deodorized oil in the Deodorizing Economizer and high pressure steam in the Final Heater. A portion of the free fatty acids in the oil will be flashed off as the oil temperature increases.

The hot oil enters the Packed Column, which is filled with special structured packing so that the oil is distributed into a thin film and is evenly agitated by stripping steam flowing counter currently from the bottom of the column. As a result, free fatty acids and other remaining volatile impurities in the oil are evaporated and removed with the steam. The residence time in the column is only a few minutes.

Next, the stripped oil enters the heat bleaching section where it flows through the channels of a series of vertically stacked compartments (trays) while agitated by stripping steam. The prolonged thermal action breaks down color bodies (carotenes) and other heat sensitive compounds are volatilized and removed, or rendered inactive, resulting in a lighter oil color. Also, the amount of remaining free fatty acids in the oil is reduced to an absolute minimum.

The deodorized oil is pre-cooled by deaerated oil and then sprayed into the Post Deodorizer where the final "off-flavor" compounds are removed.

Fatty acids and other materials, evaporated from the oil, are condensed by contact with recycled and cooled distillate in the Vapor Scrubbing section. The soybean oil deodorizer distillate is circulated by the Distillate Pump via the Distillate Cooler where it is cooled by cooling water. Accumulated distillate is discharged from the Scrubber to storage.

SODD is a by-product of deodorization and is a complex mixture of free fatty acids, mono-, di- and triacyglycerols, sterols and their esters, tocopherols, hydrocarbons, pesticides, and breakdown products of fatty acids, aldehydes, ketones and acylglycerol species (Ramamurthi \& McCurdy, 1993, Verleyen, 2001c). SODD corresponds between 0.1 and $0.4 \%$ of crude soybean oil. Deodorizer distillate is an excellent source of valuable compounds such as phytosterols and tocopherols, corresponding approximately $10 \%$ and $20 \%$ respectively (Czuppon et al., 2003), which can be recovered and further used as food additives, in pharmaceutical industry and cosmetics (Lin \& Koseoglu, 2003). Their commercial value however, is mainly dependent on their tocopherol content, depending on the market demand for this ingredient (Dumont \& Narine, 2007).

SODD contains high levels of free fatty acids and acylglycerols (Chu et al., 2002). Fatty acids represent $25-75 \%$ and acylglycerols about 3-56\% of Vegetal Oil Deodorizer Distillates (VODD), depending on the raw material being refined and on the type and conditions of the refining process (Ramamurthi \& McCurdy, 1993). The free fatty acids from deodorizer distillate are mostly used as additives for animal food, fluidizing agents for lecithin or as medium-grade soaps. Such fatty acids also can be used as precursors in a wide variety of 
molecular synthesis schemes such as the production of dibasic acids of different chain lengths (Gangopadhyay et al., 2007). Alternatively, deodorizer distillate have non-food applications, such as biodiesel or can be used mixed with the fuel oil to fire the steam boilers (Svensson, 1976).

Tocopherols (vitamin E) are natural antioxidants found in vegetable oils and contribute significantly to their oxidative stability. Due to the high tocopherol content of crude oils, they can be stored long periods of time if they are protected from air, moisture and high temperature (Norris, 1979) without any significant deterioration. However, the concentration of natural tocopherols in soybean oil is too high for optimum oxidative stability and flavor, because they can act as pro-oxidants by peroxide formation (Jung \& Min, 1990, Warner, 2005).

Moreover, tocopherols exert several beneficial activities, such as protective role of vitamin A, $\beta$-carotene and essential fatty acids (Ferrari et al., 1996). Tocopherols also prevent diseases like cancer (Kline et al., 2007), cardiovascular and cataracts (Block \& Langseth, 1994, Munteanu \& Zingg, 2007, Rimm et al., 1993). They are used in food, cosmetics and pharmaceutical industries (Chu, 2002) and a mixture of $\alpha, \beta, \gamma$ and $\delta$ isomers containing 60 $\mathrm{wt} \%$ tocopherols is widely used as additive to many kinds of foods (Shimada, 2000).

On other hand, in recent years a significant number of reports, patents, and scientific publications describing improved methods for phytosterol recovery and purification have been developed. This phenomenon is closely related to the growing market for phytosterols, particularly given the widespread dissemination of functional foods (Fernandes \& Cabral, 2007).

Phytosterols are useful hypocholesterolemic agents since a daily intake of 2-3 g lowers LDL cholesterol concentrations by $10-15 \%$ as found in various populations (Kritchevsky \& Chen, 2005, Quílez et al., 2003). The proposed mechanism is that plant sterols reduce the micellar solubility of cholesterol and consequently lower intestinal absorption of both exogenous and endogenous cholesterol (de Jong et al., 2003, Trautwein et al., 2003), but also experimental investigations suggest that sterols may act modulating lipid and protein metabolism (Mulligan et al., 2003, Plat \& Mensink, 2005). In addition to their cholesterol lowering effect, plant sterols may possess anti-cancer (Awad et al., 2003), antiatherosclerosis (Moghadasian et al., 1999, Moghadasian et al., 1997), anti-inflammation (Bouic, 2001) and antioxidation activities (van Rensburg et al., 2000). Phytosterol compounds exhibit virtually no side effects and they have shown no evidence of in vitro mutagenic activity or subchronic toxicity in animals (Rozner, 2006). These compounds have been extensively used as a food ingredient in the functional food industry.

Moreover, phytosterols are valuable precursors in the production of hormones (Donova, 2007). They are used in manufacturing progesterone, corticoids, estrogens, contraceptives, diuretics, male hormones and vitamin D. They are, also, used in cosmetics (Balazs, 1987, Fernandes \& Cabral, 2007).

Another important bioactive compound concentrated in intermediate byproducts and waste streams during the refining of soybean oil, is squalene, a hydrocarbon that has been used in applications such as natural moisturizer in cosmetics and biochemical precursor in the synthesis of steroids. Recently, steroidal hydrocarbons and squalene in soybean oil deodorizer distillate have been isolated and identified. Separation, purification, and chemical characterization of hydrocarbons fraction in soybean oil deodorizer distillate will help researchers finding a better utilization of these byproduct (Gunawan, 2008b, Kasim, 2009). 
The refining process induces changes in the structure and concentration of tocopherols, sterols (free and bound) and squalene.

Of these various components, most attention is given to the tocopherols. Jung and coworkers (Jung et al., 1989) and Ferrari (Ferrari, 1996) have studied the tocopherol content at all stages of processing for all isomers in the finished oil. The tocopherol content decreases during each step of processing and may be markedly reduced during deodorization, as the tocopherols are volatile under these conditions. The processing removed between 30-60\% of tocopherols in crude soybean oil. Even though total tocopherol content decreased during processing, the relative compositions of tocopherols in soybean oils were constant during processing.

Sterol content present in soybean oil also tend to be diminished in processing and the magnitude of such decrease is about the same as the tocopherols (Ferrari, 1996). It has been shown that the absorption of sterols is increased extensively with increased amounts of bleaching clay. The lipid extract from the bleaching clay had high concentrations of sterols in unchanged form.

Squalene content also decreases during processing (Nergiz \& Çelikkale, 2010), but not drastically until deodorization, when it is partially volatilized. Total losses during all the stages of refining were found to be $31 \%$ as compared to its content in crude soybean oil.

Numerous procedures have been described to isolate bioactive compounds from soybean oil deodorizer distillate to improve the value and the quality of this by-product. All these procedures can be grouped in four generic categories: classic method such as crystallization and precipitation, molecular distillation, supercritical fluid extraction and chemical and enzymatic modification.

\section{Classic methods to obtain functional lipids from SODD}

In the past, recovering tocopherols and sterols from deodorizer distillates and related mixtures has been proved to be complicated and expensive. One difficulty associated with isolating one or more distillate fractions enriched in fatty acids, tocopherols, and/or sterols from deodorizer distillates is that the molecular weights and volatilities of sterols are similar to those of tocopherols (Ghosh \& Bhattacharyya, 1996). For this reason, it is difficult to recover concentrates of tocopherols and phytosterols with good yield and high quality (Lin, 2002). In addition, in order to separate the squalene present in the distillate, the main challenge is to isolate them from each other, especially in the case of the following pairs of components: tocopherol-squalene, tocopherol-fatty acids, tocopherol-sterol and sterolsqualene.

Another difficulty is that deodorizer distillate can undergo thermal degradation if it is processed for extended periods at the temperatures at which sterols and tocopherols vaporize, such temperature conditions which can cause fatty acids to convert into undesirable trans isomeric forms and may cause the degradation of tocopherols (Chu, 2002).

Classical methods for recovering tocopherols and sterols include solvent extraction, chemical treatment, crystallization, complexation, and molecular distillation (Rohr \& Trujillo-Quijano, 2005). The separation process involves a series of chemical and physical techniques which are used alone or in combination. In general, most processes are designed to remove either fatty acids or sterols in the initial step, followed by tocopherol concentration by other methods. 
Crystallization has frequently been used to purify sterols from SODD, either following or preceding other separation methods. Brown (Brown \& Smith, 1964) reported a phytosterols product prepared by a continuous two-stage liquid-liquid extraction (LLE) with a solvent pair of methanol and hexane, and then followed by crystallization using acetone as a solvent at $4{ }^{\circ} \mathrm{C}$ for $24 \mathrm{~h}$. By this approach, $73 \%$ sterol concentrate was obtained from SODD containing 6.5\% sterol. Sheabar and Neeman (Sheabar \& Neeman, 1987) have shown the preparation of a tocopherol concentrate through removal of sterol from SODD by a twostage crystallization at $-20^{\circ} \mathrm{C}$ with hexane and acetone as crystallization solvents. Attempts have been made to isolate tocopherols from SODD by supercritical fluid extraction technology with crystallization as pretreatment to first remove sterols (Lee et al., 1991). SODD was esterified with methanol using $\mathrm{HCl}$ as catalyst, then a solvent pair of hexanemethanol was used to obtain tocopherols-sterols concentrate from which sterols were recovered by crystallization at $-20^{\circ} \mathrm{C}$ with acetone as a solvent (Brown \& Smith, 1964). The results were similar to those mentioned above. Nevertheless, the information of total yield of sterols was not provided in these publications.

Crystallization seems successful as a simple and efficient process to remove and concentrate sterols and tocopherols from SODD. This process has the advantage of not causing tocopherol oxidation, because the low temperature utilized, and it does not use high pressure. While there is much information in the literature on the recovery of sterols from SODD by crystallization, little attempt is made pertaining to its optimal conditions such as solvent type, crystallization temperature and time. Lin and Koseoglu (Lin \& Koseoglu, 2003) have shown crystallization of sterols from SODD without any pretreatment is practical. The best results were achieved by crystallization at $-20{ }^{\circ} \mathrm{C}$ for $24 \mathrm{~h}$ using a solvent mixture of acetone-methanol $(4: 1, \mathrm{v} / \mathrm{v})$ at a solvent-to-SODD ratio of $3: 1(\mathrm{v} / \mathrm{w})$, followed by centrifugation, filtration, and twice washing of the wet cake. Over $90 \%$ of the original tocopherols and squalene, were retained in the filtrate fraction, while $80 \%$ of the original sterols were crystallized in the cake fraction. Khatoon and coworkers (Khatoon et al., 2010) developed a method for the preparation of phytosterols from SODD by crystallisation using hexane and water. Direct crystallisation yielded a phytosterol fraction with lower recovery of $13.2-17.8 \%$ while treatment with alkali to remove FFA and the glycerides followed by organic solvent extraction yielded unsaponifiable matter containing phytosterols with a recovery of $74.6 \%$. Later the unsaponifiable matter was purified by double crystallisation into a mixture of phytosterols of $87 \%$ purity. Moreira and Baltanás (Moreira \& Baltanás, 2004) studied the impact of the principal process variables (solvents and cosolvents, cooling rate, crystallization temperature, and ripening time) on the quality and yield of the recovered phytosterols, but in this case by using a sunflower oil deodorizer distillate "enriched" (i.e., preconcentrated). In this study, a sterols recovery as high as $84 \%$ (with $36 \%$ purity) was achieved by using a single-stage batch crystallization of hexane/ethanol mixture (ratio of $4: 1, \mathrm{v} / \mathrm{v}$ ) at $-5^{\circ} \mathrm{C}$.

On the other hand, a modified industrial process was developed by $\mathrm{Xu}$ and coworkers $(\mathrm{Xu}$ et al., 2005) to recovery and purify valuable compounds from SODD. In this process, tocopherols and fatty acids methyl esters (FAMEs) was obtained from SODD after a process with methyl esterification by sulfuric acid catalyst, transesterification by alkaline catalyst, crystallization of sterols and molecular distillation. The waste residue of SODD was obtained after the molecular distillation and it mainly contains steryl esters, acylglycerols, and hydrocarbons. 
In turn, Yang and coworkers (Yang et al., 2009) developed a catalytic and crystallization process to recover phytosterols from waste residue of SODD (WRSODD). A catalyst was employed to decompose WRSODD so as to transform steryl esters into phytosterols. The mixed solvent that generated the best crystallization results was acetone and ethanol $(4: 1$, $\mathrm{v} / \mathrm{v}$ ). The yield and the purity of recovered phytosterols were $22.95 \mathrm{wt}$. \% and $92-97 \%$, respectively.

Nevertheless, crystallization has the disadvantage of the solvents available at present are not sufficiently selective to obtain, through the current processes, a reasonable separation between the unsaponifiable components and free fatty acids. Due to this, it is often necessary to use more than one solvent, which in turn complicates and increases tremendously the cost of recovery and recycling of these solvent mixtures. Furthermore, solvents or solvent mixtures are used in very large proportions, when compared to the quantity of the material submitted for extraction, and the solvents need additional processes for their removal and/or recycling in the extraction and pre-concentration process of the valuable products. The foregoing reasons make solvent based-processes, expensive, unattractive and less environmentally friendly, resulting in a scarce and expensive final product.

Saponification is also a common practice to concentrate tocopherols and sterols since it produces alkali metal soap which, due to its insolubility in the solvent used in the process, can be separated from the dissolved tocopherols, thereby permitting recovery of the tocopherols in a form relative free from fatty acids and glycerides. The processes themselves are costly, however, and tocopherols are produced in low yield. The sterols are then isolated from the resulting concentrate mixture by crystallization (Brown \& Meag, 1963, Kijima et al., 1964, Kim \& Rhee, 1982).

Of the saponification processes, the lime saponification process is the most widely used. Hickman, U.S. Patent No. 2.349.270 (Hickman, 1944), discloses that deodorizer distillate can be treated with calcium hydroxide, traditionally called slaked lime, to saponify the fatty acids, followed by extraction of the unsaponifiable fraction (tocopherols and sterols) with acetone, in which the saponification products are insoluble. The extract is then washed and concentrated, as for example by solvent distillation, and then cooled to crystallize sterols which are removed by filtration, leaving a high purity tocopherol fraction. The fatty acid soaps formed by the process can be acidulated and converted into free fatty acids. Andrews, U.S. Patent No. 2.263.550 (Andrews, 1941), discloses saponification of deodorizer distillates with sodium hydroxide, followed by metathesis (a molecular process involving the exchange of bonds between the two reacting chemical species, in this case a ion exchange) with calcium chloride to convert the sodium soaps to calcium soaps (not water soluble), from which the tocopherols and other unsaponifiable matter are then extracted with acetone.

The disadvantage of each of these processes is that the calcium soap is formed in a wide particle size distribution, ranging from fine particles to lumps. The result is a soap mass which is lumpy in form and from which the unsaponificable matter is difficult to extract. To permit the extraction to take place, the soap mass must be ground into particulate form, a process which entails a substantial capital investment. Even then, solvent consumption is high and the recovery of tocopoherols and other useful unsaponificable matter such as sterols is low.

Grinding is avoided in the process disclosed by Brown and coworkers (Brown \& Meag, 1963), which uses calcium silicate as a powdering agent in combination with acetone to 
facilitate the separation of the soluble tocopherols and sterols from the insoluble soap mass. Unfortunately, this process requires a large amount of powdering agent which remains in the soap mass, and the effectiveness of the powdering agent is diminished if the moisture content of the soap mass is too high.

Although saponification is effective to remove free fatty acids and acylglycerols, it involves the use of a large amount of alkali which is harmful to tocopherols, thus leading to low yields. Recently, molecular distillation combined with crystallization was more attractive to separately concentrate tocopherols and sterols (Gapor et al., 1989, Hunt et al., 1997, Kijima, 1964, Kim \& Rhee, 1982, Smith Frank, 1967). To increase the separation efficiency, esterification and/or transesterification are usually carried out prior to molecular distillation. Free fatty acids and acylglycerol are converted to fatty acid methyl esters, which are more easily removed by vacuum distillation due to their higher vapor pressure than those of the corresponding free fatty acids and acylglycerol. However, this step made the whole process more complicated and labor-intensive when compared with the saponification process. Another drawback of molecular distillation is that it is energy consuming to maintain high vacuum all of the time during operation. Consequently, the final product is also expensive.

\section{Enzymatic modification}

Enzymatic reactions are based on the selective biotransformation of determined compounds in order to modify their chemical or physical properties. Hence, the utilization of enzymes, for instance, makes easier the separation of tocopherols from SODD by converting sterols to steryl esters, acylglycerols to free fatty acids and free fatty acids to fatty acid methyl or ethyl esters (FAMEs or FAEEs). Then, it is easier to separate the new product mixture by distillation or supercritical fluid extraction. From published literature, it can be point out that the main difficulties of the enzymatic processes are the numerous parameters involved such as moisture content, enzyme concentration, time, temperature, ratio of the reactants, stability, recovery and reutilization of the enzyme preparation, among others (Ramamurthi et al., 1991), (Ramamurthi \& McCurdy, 1993).

The conversion of FFAs to FAMEs or FAEEs is an important step in the concentration and purification of tocopherols. If this step is omitted, the separation of FFA and tocopherols by distillation cannot be achieved due to their similar boiling points (Shimada, 2000). Furthermore, if methanol is used for the biotransformation of FFA to FAMEs, concomitant sterol esterification with fatty acids is inhibited. To avoid this problem, a lipase can be used in a two stages procedure: first to carry out hydrolysis of acylglycerols and then to promote the esterification of sterols with free fatty acids. The different components are then successfully separated by short path distillation or supercritical fluid extraction since their boiling points are now sufficiently different.

In the literature, many enzymatic procedures for the preparation of sterol esters are described, but most of them require organic solvents, water and molecular sieves or other drying agents (Haraldsson, 1992), (Shimada et al., 1999), (Jonzo et al., 1997), (Hedström et al., 1992). Although these strategies gave good conversion rates for the formation of sterol esters, the use of such multiphasic systems may complicate the final purification of the products in the case of larger scale productions. However, the enzymatic preparation of fatty acid esters of sterols, stanols and steroids in high yield by esterification and transesterification of fatty acids and other carboxylic acid esters, in vacuum at moderate 
temperature using immobilized lipases have been also reported (Weber et al., 2001). In this case neither organic solvent, nor water or any drying reagent such as molecular sieves, are used. This and others studies (Shimada, 2000) showed that in the process of esterification of sterols with free fatty acids, the best results are obtained with Candida rugosa lipase and Pseudomonas sp. However, enzymatic conversion of FFAs to FAMEs or FAEEs is carry out frequently in the presence of Candida antactica lipase or Alcalygenes sp. (Torres, 2007), (Nagao et al., 2005).

In the following paragraphs some examples of methodologies using enzymes in the pretreatment of SODD are described. Most of them will be further developed in following sections:

Shimada and coworkers (Shimada, 2000) converted sterols from SODD to fatty acid sterol esters and completely hydrolyzed acylglycerols by applying lipase reactions (Candida rugosa or Pseudomonas sp., at $35^{\circ} \mathrm{C}$ for $24 \mathrm{~h}$ ) to the purification of tocopherols and sterols, resulting in an efficient fractionation of tocopherols and sterols as fatty acids steryl esters (FASEs) by short-path distillation. This process included the drawback that FFA and tocopherols were not efficiently fractionated because the boiling points of the two substances were close. This problem could be solved by conversion of the FFA to their corresponding methyl esters. An attempt to develop a reaction system in which the methyl esterification of FFA proceeded simultaneously with the conversion of sterols to FASEs and the hydrolysis of acylglycerols has been also reported (Watanabe et al., 2004).

Nagao and coworkers (Nagao, 2005) and Watanabe and coworkers (Watanabe, 2004) have applied a procedure based on using a lipase to promote the simultaneous esterification of sterols with free fatty acids and hydrolysis of acylglycerols before the esterification of the free fatty acids with methanol. These authors use Candida rugosa lipase for the purification of tocopherol in SODD. Watanabe and coworkers reported $80 \%$ conversion of the initial sterols to FASEs, complete hydrolysis of the acylglycerols, and a $78 \%$ decrease in the initial FFA content by methyl esterification in $40 \mathrm{~h}$. Tocopherols did not change throughout the process. Distillation of the reaction mixture purified tocopherols to $76.4 \%$ (recovery, 89.6\%) and sterols to $97.2 \%$ as FASEs (recovery, $86.3 \%$ ). Nagao and coworkers reported a more effective sterols esterification, with a degree of esterification reached $95 \%$. The second-step reaction was then conducted at $30^{\circ} \mathrm{C}$ for $20 \mathrm{~h}$ with Alcaligenes sp. lipase. 95\% FFAs were converted to FAME, and steryl esters synthesized by the first-step reaction were not reconverted to free sterols. Finally, tocopherols and steryl esters were purified from the reaction mixture by short-path distillation. Tocopherols were purified to $72 \%$ (yield, $88 \%$ ) and steryl esters were purified to $97 \%$ (yield, 97\%). One of the main disadvantages of this method is that the remaining free fatty acids are not completely separated from the tocopherols.

Lipase-catalyzed esterification of sterols and ethyl esterification simultaneously, are governed by the concentration of water present. The degree to which esterification of sterols occurs relative to ethyl esterification requires to attain a balance not always easy to achieve because the presence of an excess of water favours hydrolysis, whereas esterification predominates when a very limited amount of water is present (Marangoni \& Rousseau, 1995). By appropriate choice of reaction conditions, however, it is possible to separate the sterol esterification and ethyl esterification in time or space. It is then possible to optimize each of these reactions independently, thereby minimizing costs or improving the yield of the desired final reaction products.

This is precisely the procedure carried out by Torres and coworkers (Torres, 2007), who proposed a two-step enzymatic procedure to obtain FASEs, tocopherols, and fatty acid ethyl 
esters (FAEEs) from SODD. Firstly, SODD was mixed with oleic acid to reduce its melting point and to enhance the free phytosterols esterification. The first enzymatic step (using Candida rugosa lipase) allowed the efficient conversion of more than $90 \%$ free phytosterols within $5 \mathrm{~h}$. The second one (using Novozym 435) converted more than 95\% FFAs in less than $3 \mathrm{~h}$. The final product obtained was used as starting material to purify FASEs, tocopherols, and FAEEs via supercritical $\mathrm{CO}_{2}$ extraction (Torres, 2009).

Weber and coworkers (Weber et al., 2002) have also reported the use of lipases for the conversion of sterols into steryl esters leading to a higher degree of purity $(90 \%)$, however the methodology is more complex and involves deacidification, flash chromatography and solvent fractionation.

Another methodology was developed to focus more specifically on the conversion of FFAs into fatty acid butyl esters (FABEs) (Nagesha et al., 2004). Nagesha and coworkers (Nagesha, 2004) used immobilized Mucor miehei lipase in supercritical carbon dioxide at high pressure and obtained a maximum recovery of $88 \%$ and a FABE purity of $95 \%$ from SODD.

\section{Molecular distillation}

Most of the substances that are present in soybean deodorizer distillate are molecules of high molecular weight and thermally sensitive. These properties hinder the separation or purification of these compounds through traditional methods, because they are decomposed when subjected to high temperatures.

An alternative separation/purification procedure of such products is the use of molecular or short-path distillation. It consists of transferring molecules from the surface of an evaporating liquid to the cooled surface of a condenser through a short path, which is on the order of $2-5 \mathrm{~cm}$. In this process, distillation of heat-sensitive materials is accompanied by only negligible thermal decomposition (Lutisan et al., 2002) because materials, by using high vacuum, are submitted to relatively reduced temperatures, and short residence times (Lutisan, 2002) inside the equipment. Furthermore, this process has advantages over other techniques that use toxic or flammable solvents as the separating agent, avoiding toxicity and environmental problems.

The combination of a small distance between the evaporator and the condenser of only a few centimetres and a high vacuum in the distillation gap, results in a specific mass transfer mechanism with evaporation outputs as high as 20-40 gm-2 s-1 (Cvengros et al., 2000). Under these conditions (e.g., short residence time and low temperature), distillation of heatsensitive materials is accomplished without or only negligible thermal decomposition. Therefore, molecular distillation shows potential in the separation, purification and/or concentration of natural products, usually constituted by complex and thermally sensitive molecules such as tocopherols.

In lipid chemistry, it has been used for the purification of monoacylglycerols (Szelag \& Zwierzykowski, 1983), recovery of carotenoids from palm oil (Batistella \& Wolf Maciel, 1998), fractionation of polyunsatured fatty acids from fish oils (Breivik et al., 1997), recovery of squalene (Sun et al., 1997), and recovery of tocopherols (Batistella et al., 2002), among others.

Normally, SODD have a high content of FFA and acylglycerol. To increase the separation efficiency of the compounds of interest, esterification and/or transesterification reactions are usually carried out prior to molecular distillation. Free fatty acids and acylglycerols are converted to fatty acid methyl esters, which are more easily removed by vacuum distillation 
due to their higher vapor pressure than those of the corresponding free fatty acids and acylglycerols. However, this step made the whole process more complicated and laborintensive when compared with the saponification process. Other problem is that the separation of tocopherols from phytosterols is difficult because they have similar molecular weights, boiling points and vapor pressure, and, consequently, they are distillated together (Ghosh \& Bhattacharyya, 1996).

Different processes have been proposed in the literature to eliminate FFA by molecular distillation and purify tocopherols and phytosterols. Most of them include a preliminary chemical or enzymatic treatment step.

Ramamurthi and McCurdy (Ramamurthi \& McCurdy, 1993) studied the pretreatment of deodorizer distillate using a lipase-catalyzed esterification reaction to convert FFA into methyl esters, followed by vacuum distillation $(1-2 \mathrm{~mm} \mathrm{Hg})$ to remove them and concentrate tocopherols and sterols (recoveries were over $90 \%$ ).

Hirota and coworkers (Hirota et al., 2003) isolated naturally occurring Fatty Acid Steryl Esters (FASEs) from SODD. SODD was firstly subjected to molecular distillation at $250{ }^{\circ} \mathrm{C}$ and $0.02 \mathrm{~mm} \mathrm{Hg}$ to obtain a residue which was rich in DAGs and TAGs, and steryl esters. Enzymatic lipolysis was then conducted to specifically hydrolyze DAGs and TAGs at $35^{\circ} \mathrm{C}$ for $24 \mathrm{~h}$, resulting in a mixture from which fatty acid steryl esters were later purified using a two-stage molecular distillation $\left(180{ }^{\circ} \mathrm{C}\right.$ and $0.2 \mathrm{~mm} \mathrm{Hg}$, and $250{ }^{\circ} \mathrm{C}$ and $\left.0.02 \mathrm{~mm} \mathrm{Hg}\right)$. The recovery and purity of FASEs were about $87.7 \%$ and $97.3 \mathrm{wt} \%$, respectively.

Purification of tocopherols from SODD was carried out by Shimada and coworkers (Shimada, 2000). SODD was distilled using molecular distillation at $250{ }^{\circ} \mathrm{C}$ and $0.02 \mathrm{~mm} \mathrm{Hg}$ and the resulting distillate was used as a starting material. Sterols in SODD were converted to FA sterol esters and acylglycerols were completely hydrolyzed by applying lipase reactions. FASEs were recovered as residue from the reaction mixture via molecular distillation at $250{ }^{\circ} \mathrm{C}$ and $0.2 \mathrm{~mm} \mathrm{Hg}$. However, the last stage of molecular distillation failed to separate FFAs and tocopherols. A second esterification of free phytosterols was applied at $35^{\circ} \mathrm{C}$ for $24 \mathrm{~h}$, followed by another four-stage molecular distillation $\left(160{ }^{\circ} \mathrm{C}\right.$ and $0.2 \mathrm{~mm} \mathrm{Hg}$, $200{ }^{\circ} \mathrm{C}$ and $0.2 \mathrm{~mm} \mathrm{Hg}, 230^{\circ} \mathrm{C}$ and $0.04 \mathrm{~mm} \mathrm{Hg}$, and $255^{\circ} \mathrm{C}$ and $0.03 \mathrm{~mm} \mathrm{Hg}$ ) which yielded tocopherols with purity and recovery of about $65.3 \mathrm{wt} \%$ and $54.6 \%$, respectively.

Watanabe and coworkers (Watanabe, 2004) isolated tocopherols and free phytosterols as their esters from SODD tocopherol/sterol concentrate (SODDTSC). SODDTSC was obtained via molecular distillation at $240{ }^{\circ} \mathrm{C}$ and $0.02 \mathrm{~mm} \mathrm{Hg}$, resulting in a distillate rich in tocopherols and free phytosterols (SODDTSC), and a residue rich in FASEs, DAGs, and TAGs. SODDTSC, which contained also MAGs, DAGs, FFAs, and unidentified hydrocarbons, were then subjected to a two-step in situ enzymatic reaction. SODDTSC were treated with Candida rugosa lipase (200 U/g activity) to convert free phytosterols to FASEs, acylglycerols (MAGs and DAGs) to FFAs, and FFAs to FAMEs at $30^{\circ} \mathrm{C}$ for $40 \mathrm{~h}$, achieving $80 \%$ conversion of the initial sterols to FA steryl esters, complete hydrolysis of the acylglycerols, and a $78 \%$ decrease in the initial FFA content by methyl esterification. Tocopherols did not change throughout the process. To enhance degree of steryl and methyl esterification, FASEs and FAMEs enriched in the reaction product were then removed by a two-step molecular distillation. In the first step, FAMEs was removed in the distillate (160 ${ }^{\circ} \mathrm{C}$ and $\left.0.2 \mathrm{~mm} \mathrm{Hg}\right)$. In the second step $\left(240{ }^{\circ} \mathrm{C}, 0.2 \mathrm{~mm} \mathrm{Hg}\right)$, FASEs was isolated in the residue and the distillate containing tocopherols, free phytosterols, and FFAs were treated again with lipase. A three-step molecular distillation of the reaction mixture purified 
tocopherols to $76.4 \mathrm{wt} \%$ purity (89.6\% recovery) and free phytosterols to $97.2 \mathrm{wt} \%$ purity as FASEs (86.3\% recovery).

Nagao and coworkers (Nagao, 2005) carried out similar steps of isolation of tocopherols and free phytosterols as FASEs from SODDTSC. SODDTSC were first treated with Candida rugosa lipase (250 U/g activity) to convert free phytosterols to FASEs at $40{ }^{\circ} \mathrm{C}$ for $24 \mathrm{~h}$, achieving about $95 \%$ conversion. Unreacted FFAs contained in the reaction mixture was then converted to FAMEs by Alcaligenes sp. lipase at $30{ }^{\circ} \mathrm{C}$ for $20 \mathrm{~h}$, achieving $95 \%$ conversion. Reaction mixture was then subjected to a four-stage molecular distillation (160 ${ }^{\circ} \mathrm{C}$ and $0.2 \mathrm{~mm} \mathrm{Hg}, 175^{\circ} \mathrm{C}$ and $0.2 \mathrm{~mm} \mathrm{Hg}, 230^{\circ} \mathrm{C}$ and $0.02 \mathrm{~mm} \mathrm{Hg}$, and $240{ }^{\circ} \mathrm{C}$ and $0.02 \mathrm{~mm}$ $\mathrm{Hg}$, respectively) to isolate tocopherols (72.3 wt\% purity, $87.6 \%$ recovery) in the third distillate fraction and free phytosterols as FASEs (97 $\mathrm{wt} \%$ purity, $97 \%$ recovery) in the last (fourth) residue.

Jacobs (Jacobs, 2005) proposed a method for recovering tocotrienols from fatty acid distillate FAD, which initially contained $1 \mathrm{wt} \%$ tocopherols and $0.3 \mathrm{wt} \%$ free phytosterols, by stripping FFAs (condition: $0.5-1.5 \mathrm{~mm} \mathrm{Hg}, 180-240{ }^{\circ} \mathrm{C}$, and $0.5-1.5 \mathrm{~min}$ ) to form a first stripped product. Short path distillation of the first stripped product gave a first distillate. Saponifying the second stripped product resulted in a saponified product with all FFA converted to FAMEs. A second short path distillation of the saponified product generated a second distillate without FAMEs. Solvent wintering (via filtration) of the second distillate gave a stripped filtrate. The stripped filtrate from the previous step is subjected to a third short path distillation at a temperature of $180^{\circ}$ and an absolute pressure of $0.01 \mathrm{~mm} \mathrm{Hg}$. The resulting final tocotrienol product, about $1 \%$ of the original feed, contains from about $50 \%$ tocotrienols, $1 \%$ sterols and $49 \%$ other unsaponifiables and unknowns. Additionally, the final product contains from about $15 \%$ to about $30 \%$ tocopherols.

Fizet (Fizet, 1996) esterified free phytosterols from deodorizer distillate with FFAs at either $180{ }^{\circ} \mathrm{C}$ for $2.5 \mathrm{~h}$ or $250{ }^{\circ} \mathrm{C}$ for $1.5 \mathrm{~h}$. Esterification product was then distilled at $120-150{ }^{\circ} \mathrm{C}$ and $0.08 \mathrm{~mm} \mathrm{Hg}$ to obtain a residue containing mostly tocopherols and FASEs and a distillate containing mostly fatty acids. The residue was then distilled again at $200-220{ }^{\circ} \mathrm{C}$ and 0.1 mbar to obtain a distillate containing mostly tocopherols and a residue containing mostly FASEs. Tocopherols enriched in distillate were then subjected to an ion exchange chromatography and FASEs enriched in residue were then subjected to an acid-catalyzed transesterification with methanol to produce free phytosterols.

Even so, some authors (Martins et al., 2006) have been trying to achieve an efficient FFA separation from SODD with the lowest loss of tocopherols by molecular distillation, without preliminary steps. This separation is difficult to achieve although is technologically viable at least at lab scale, due to the differences between molecular weights and vapour pressures of FFA (MW $180 \mathrm{~g} \mathrm{~mol}^{-1}, \mathrm{VP}$ at $200{ }^{\circ} \mathrm{C}=4 \mathrm{~mm} \mathrm{Hg}$ ) and tocopherols (MW $415 \mathrm{~g} \mathrm{~mol}^{-1}$, VP at 200 ${ }^{\circ} \mathrm{C}=0.15 \mathrm{~mm} \mathrm{Hg}$ ). Martins and coworkers (Martins, 2006) employed molecular distillation at $160^{\circ} \mathrm{C}, 7.5 \times 10^{-4} \mathrm{~mm} \mathrm{Hg}$, and $10.4 \mathrm{~g} / \mathrm{min}$ feed flow rate to remove FFAs into the distillate fraction and obtain a residue fraction, which contained $6.4 \mathrm{wt} \%$ FFAs and $18.3 \mathrm{wt} \%$ tocopherols from a SODD feed which contained $57.8 \mathrm{wt} \%$ FFAs and $8.97 \mathrm{wt} \%$ tocopherols. They succeeded in removing $96.16 \%$ FFAs and recovering $81.23 \%$ tocopherols. Martins and coworkers (Martins et al., 2005) reported the isolation of tocopherols by first converting acylglycerols in SODD into FFAs through saponification at $65^{\circ} \mathrm{C}$ followed by acidulation, and then submitting the unsaponifiable product to five stages of molecular distillation. They succeeded in enriching tocopherols ( $34.14 \%$ purity) by 5.8 times. The major disadvantage in these cases is the residual free fatty acids in the tocopherol mixture. 
Among the great variety of processes that have been patented for the purification of the compounds of the SODD, only the processes of esterification of fatty acids and acylglycerols with methanol or ethanol followed by high vacuum distillation, have been developed on a commercial scale for the concentration of tocopherols (Takagi \& Kai, 1984), (Su-Min et al., 1992), (Yong-Bo et al., 1994), (Rohr \& Trujillo-Quijano, 2002). These processes are the most time efficient and economical methods, however high purity of sterols or tocopherols cannot be achieved due to the similar boiling points of these two substances.

In the case of separation by distillation of unsaponifiable valuable products of SODD subjected to saponification, the difference between the boiling point of volatile products, such as unsaponifiable components, and the boiling point of the sodium and potassium organic acid soaps is so great that separation is theoretically possible at a high level of efficiency. However, a problem related to this separation technique is that the soaps have a very high melting point, close to the decomposition temperature of the sodium or potassium soaps (i.e. the sodium or potassium salts of fatty acids, rosin acids etc), and, when melted, these soaps produce an extremely viscous liquids. These two factors combined make industrial handling difficult. Furthermore, while at the high temperature necessary to maintain their flow, these soaps are in permanent decomposition, compromising the separation output and the quality of the final product, as many of the unsaponifiable valuable products are heat sensitive.

\section{Supercritical fluid extraction (SFE)}

Although the conventional methods, vacuum and molecular distillation, have been applied to commercial production of tocopherols from SODD, there are some drawbacks such as residual solvents, high temperature, large amounts of energy consumption, high production costs and the unreliable quality of the products that require further developments. Since thermal degradation of tocopherols is commonly caused by processing at high temperatures (de Lucas et al., 2002), new alternative isolation techniques are desired.

Supercritical carbon dioxide extraction is a process where carbon dioxide passes through a mixture of interest at a certain temperature and pressure until it reaches an extractor. This process is used because supercritical carbon dioxide has a low viscosity, a high diffusivity and a low surface tension that provides selective extraction, fractionation and purification, allowing its penetration in micro- and macro-porous materials. Carbon dioxide is the most desirable supercritical fluid solvent for the separation of natural products used in foods and medicines because of its inertness, nontoxicity, low cost, and high volatility. The major advantage of this method is the easy post-reaction separation of the components by depressurization, so resultant extract does not contain solvent residue and hence naturalquality extracts can be obtained. Another advantage is the low temperatures used for the majority of the experimentations because carbon dioxide has a near-ambient critical temperature $\left(31.1^{\circ} \mathrm{C}\right)$, so is suitable for thermolabile natural products.

However, the use of high pressure conditions to concentrate tocopherols makes the system energetically expensive, but the industrial process can be economically viable using conditions of approximately $90 \mathrm{~atm}$ and $40^{\circ} \mathrm{C}$ (Mendes et al., 2002). At these specific conditions, only fatty acids are separated from tocopherol (Mendes et al., 2005). An increase in pressure and temperature increases the oil extraction and tocopherol recovery, although different pressure-temperature systems need to be used in order to separate the different components (sterols, tocopherols, fatty acids and squalene). It is important to know that 
recycling the solvent does not endanger the viability of the process. The value of the rate of return on investment and time of return on investment for the process that does not recycle the carbon dioxide is higher than those of recycling the solvent. This is due to the compression cost that represents more than $59 \%$ of the total cost of the production (Mendes, 2002).

SODD as such will not be feasible to work with $\mathrm{SC}-\mathrm{CO}_{2}$ for the tocopherol enrichment, owing to its poor SC- $\mathrm{CO}_{2}$ solubility. So, to concentrate tocopherols from SODD, pretreatment of the raw material, including the esterification of free fatty acids and the removal of sterols with alcohol recrystallization, is needed to obtain the primary tocopherols concentrate with improve solubility in $\mathrm{SC}-\mathrm{CO}_{2}$ (Shishikura et al., 1988). For that, triglycerides and FFAs which constitute a major component in SODD have to be chemically modified to obtain free fatty acids and then their methyl esters by esterification.

Several researchers have tried to concentrate tocopherols from SODD by supercritical $\mathrm{CO}_{2}$ (Lee, 1991), (Brunner et al., 1991), (Brunner, 1994b), (Zhao et al., 2000), (Nagesha, G. K. et al., 2003), (Fang et al., 2007), but the operation parameters, especially pressure, differ from author to author. Moreover, in all the cases, tocopherols content of the extract depended on the composition and properties of the natural matrix.

The interest in the tocopherol concentration using supercritical fluid extraction started with Lee and coworkers (Lee, 1991) followed by Brunner and coworkers (Brunner, 1991) and Brunner (Brunner, 1994b). The operational conditions used varied from 35 to $90{ }^{\circ} \mathrm{C}$ and from 200 to 400 bar using extractors or countercurrent columns. Lee and coworkers (Lee, 1991) attempted to modify soybean sludge chemically, to improve the solubility in $\mathrm{SC}-\mathrm{CO}_{2}$. A simple batch process was utilized to recover tocopherols at $40 \%$ concentration at a pressure of 400 bar from the esterified soybean sludge which initially contained $13-14 \%$ tocopherols. The solubility of the esterified soybean sludge in supercritical carbon dioxide was more than 4 to 6 times higher than that of the sterols. Brunner and coworkers (Brunner, 1991) obtained a higher enrichment of tocopherols from SODD using supercritical carbon dioxide as a solvent compared to results obtained by Lee and coworkers This group recovered tocopherols from a model mixture of squalene, tocopherols, and sterols using two continuous countercurrent fractionation columns. Squalene was separated from the model mixture in the first column. Sterols were removed from the bottom of the second column, resulting in $85-95 \%$ concentration of tocopherol being obtained at the top of the second column.

These works concluded that the fatty acids are extracted initially and the tocopherols are enriched inside the extractor. The results also indicated that the solubility of the tocopherols is intermediary when compared to the solubilities of squalene and stigmasterol.

Chang and coworkers (Chang, 2000) worked on the separation of several SODD components. Their supercritical fluid extraction apparatus had a separation and an extraction unit. Free fatty acids, squalene and tocopherols were recovered in the extract and the sterols were recovered in the raffinates. The average tocopherol concentration factor was 1.38, which means that the mixture in the extract did not separate. However, the author mentioned that with the increase of $\mathrm{CO}_{2}$ volume, the separation factor can reach 1.7 , but the poor increase in the concentration factor does not justify the raise in gas volume. The following research groups focused on the separation of the problematic pairs by supercritical fluids using synthetic mixtures: (Mendes, 2005), (Mendes et al., 2000), (Wang et al., 2004), (Nagesha, 2004) and (Nagesha, 2003). 
There are some interesting relationships and conclusions that can be deduced from the results obtained by Mendes (Mendes, 2005, Mendes, 2000) and Chang (Chang, 2000) regarding the yield and concentration factor of pairs of compounds at different conditions of pressure and temperature. The binary mixture of tocopherol and squalene cannot be separated at low pressure conditions. An acceptable separation needs a raise in pressure to almost 203 bar ((Mendes, 2005) and (Mendes, 2000)). However, a recovery of $90 \%$ and a purity of $60 \%$ of a-tocopherol has been achieved using a pressure swing adsorption (PSA) device, that is a widely used process in the separation of gas mixtures for air-drying, oxygen and nitrogen separation of air, hydrogen purification, and various other separations. The PSA process is based on the regeneration of adsorber by the difference in adsorbed amounts of gas solute as a function of pressure. In the case of a two-bed process, one bed is in the adsorption step, while the other is simultaneously in the desorption step. The adsorption and desorption steps had pressure conditions of 160 and300 bar, respectively (Wang, 2004).

The ternary mixture of tocopherol, fatty acids and squalene behaved differently from the tocopherol-fatty acid binary mixture. For the same conditions of pressure (160 and 300 bar), the binary mixture had a total separation while the ternary mixture did not achieve any separation. Squalene and stigmasterol mixtures are also very difficult to separate. At low pressure conditions, the yield is less than $10 \%$ but at higher pressure, the yield is $76 \%$. It is important to note that low temperatures were used in these studies.

Results of these authors suggest that the supercritical- $\mathrm{CO}_{2}$ process could be used for the separation of squalene, fatty acids and tocopherols. In order to enhance the squalene, fatty acids and tocopherols separation, deodorizer distillate mixtures should be processed several times in supercritical- $\mathrm{CO}_{2}$ at different temperature and pressure conditions. However, there is no data reported regarding the total extraction time of the mixture and this makes it impossible to estimate the operational cost. The major advantage of this method is the total removal of free fatty acids from the mixture.

Zhao and coworkers (Zhao, 2000) concentrated tocopherols up to $75 \%$ at 120 bar using a fractionation column with a gradient of temperature from $30-80^{\circ} \mathrm{C}$ in a pilot plant scale.

Nagesha and coworkers (Nagesha, 2003) performed chemical modification of SODD containing about $2.9 \mathrm{wt} \%$ of tocopherols, as well as triglycerides (56 wt \%), free fatty acids (25.3 wt\%), sterols $(7.8 \mathrm{wt} \%)$, hydrocarbons $(0.6 \mathrm{wt} \%)$, and unsaponifiables $(6.4 \mathrm{wt} \%)$ apart from tocopherols. Chemical modification of SODD included saponification and esterification steps to result in fatty acid methyl esters from free fatty acids, so as to improve the solubility of SODD in SC- $\mathrm{CO}_{2}$ extraction. Reactions were conducted in dark with continuous flushing of $\mathrm{N} 2$ and $1.0 \mathrm{wt} \%$ of pyrogallol was added to prevent the oxidation of tocopherols. After chemical modification, esterified SODD contained about $3.7 \mathrm{wt} \%$ of tocopherols. Tocopherols concentrates of about $36 \%$ was obtained by $\mathrm{SC}-\mathrm{CO}_{2}$ extraction at the pressure 180 bar and temperature $60{ }^{\circ} \mathrm{C}$.

Fang and coworkers (Fang, 2007) carried out a pretreatment of methyl esterification and methanolysis reactions, which converted most of free fatty acids and glycerides to fatty acid methyl esters (FAMEs), respectively, to simplify the composition of SODD and improve his solubility in supercritical $\mathrm{CO}_{2}$ extraction. The mixture was held at $3{ }^{\circ} \mathrm{C}$ in a refrigerator for $12 \mathrm{~h}$, as a result most of sterols were crystallized and removed by filtering under a reduced pressure. Supercritical $\mathrm{CO}_{2}$ fractionation was employed to concentrate tocopherols from Methyl Ester Oil Deodorizer Distillate (ME-DOD) product, mainly contained FAMEs (65$80 \mathrm{wt} . \%$ ), tocopherols (10-15 wt.\%), and impurities (such as residual sterols, glycerides, squalene, pigments, and long chain paraffins, comprising in total about 10-15 wt.\%). The 
initial pressure, feed location, temperature gradient, and ratio of $\mathrm{CO}_{2}$ to ME-DOD were optimized for separating FAMEs. For the following tocopherol concentration step, a final pressure of 200 bar resulted in the greatest average tocopherol content $(>50 \%)$ and tocopherol recovery (about $80 \%$ ).

The important step in concentrating natural tocopherols from these systems is to remove the FAMEs. FAMEs are important chemical materials in biofuel, metal-cutting oil, and cleaning agent production, as well as in the synthesis of other fatty acid products (Swern, 1986).

Some works on phase equilibrium for the realistic system of modified esterification SODD/supercritical $\mathrm{CO}_{2}$ (Fang et al., 2005) established that the separation factor ${ }^{1}$ between tocopherols and FAMEs was always smaller than unity in the range investigated. This indicates that when supercritical $\mathrm{CO}_{2}$ is used as the separation solvent, tocopherols, unlike FAMEs, tend to enrich in the liquid phase. In particular, the separation factors at pressures lower than 200 bar were relatively small. At $40^{\circ} \mathrm{C}$, for instance, the separation factor remained lower than 0.2 for all pressures lower than 150 bar. As pressure increased, the separation factor increased greatly, reaching 0.35 at 200 bar. The influence of temperature was contrary to that of pressure, with an increase in temperature leading to a decrease in separation factor. Low pressure and high temperature result in high selectivity, indicated by a low separation factor, which is advantageous in the separation of FAMEs from tocopherols with supercritical $\mathrm{CO}_{2}$.

King and coworkers (King et al., 1996) combined supercritical fluid extraction (SFE) with supercritical fluid chromatography (SFC) for concentrating tocopherols and the optimized conditions were $250 \mathrm{bar} / 80^{\circ} \mathrm{C}$ for SFE and $250 \mathrm{bar} / 40^{\circ} \mathrm{C}$ for SFC. Approximately $60 \%$ of the available tocopherols in soyflakes can be recovered in the SFE step, yielding enrichment factors of 1.83-4.33 for the four tocopherol species found in soybean oil. Additional enrichment of tocopherol species can be realized in the SFC stage, with enrichment factors 2 ranging from 30.8 for delta-tocopherol to 2.41 for beta-tocopherol.

Starting with a feed containing $48.3 \mathrm{wt} \%$ tocopherols, Gast and coworkers (Gast et al., 2005) were able to obtain tocopherols with a purity of $94.4 \mathrm{wt} \%$ in bottom phase by supercritical $\mathrm{CO}_{2}$ extraction at 230 bar and $80{ }^{\circ} \mathrm{C}$, with a solvent-to-feed ratio of 110 and a reflux ratio of 4.6. Squalene was completely recovered in top phase.

Torres and coworkers (Torres, 2007) proposed a two-step enzymatic procedure to obtain FASEs, tocopherols, and fatty acid ethyl esters (FAEEs) from SODD, together with minor amounts of squalene, free fatty acids, free sterols and triacylglycerols. The final product obtained was used as starting material to purify FASEs, tocopherols, and FAEEs via supercritical $\mathrm{CO}_{2}$ extraction The phytosterol esters were then purified from this mixture using supercritical carbon dioxide (Torres, 2009). Experimental extractions were carried out in an isothermal countercurrent column (without reflux), with pressures ranging from 200 to $280 \mathrm{bar}$, temperatures of $45-55^{\circ} \mathrm{C}$ and solvent-to-feed ratios from 15 to $35 \mathrm{~kg} / \mathrm{kg}$. Using these extraction conditions, the fatty acid esters were completely extracted and, thus, the fractionation of tocopherols and phytosterol esters was studied. At 250 bar, $55^{\circ} \mathrm{C}$ and a

\footnotetext{
1 The separation factor represents the process selectivity for separating methyl oleate from tocopherol. In detail, a lower value indicates higher selectivity, whereas a higher value indicates that it is more difficult to separate the two compounds under certain conditions. Furthermore, when the separation factor equals unity, the composition in the gas phase is similar to that in the liquid, and the supercritical $\mathrm{CO}_{2}$ process cannot separate methyl oleate from tocopherol.

${ }^{2}$ The enrichment factors were the ratio of individual tocopherols in extracts versus the same tocopherol content initially found in the soyflakes.
} 
solvent-to-feed ratio of 35 , the phytosterol esters were concentrated in the raffinate up to $82.4 \mathrm{wt}-\%$ with satisfactory yield $(72 \%)$.

Other supercritical fluids have been explored but unsuccessfully for the separation of different pairs of components. An attempt at using similar methodology to (Mendes, 2000) and (Mendes, 2005) but using liquid gas petroleum instead of carbon dioxide did not change the poor concentration factor between the critical pairs of components (Buczenko et al., 2003). Buczenko and coworkers (Buczenko, 2003) performed the saponification of the raw material and the extraction of unsaponifiable matter as pre-treatment of VODD.

As discussed above, there are a lot of experimental studies proving the efficiency of the supercritical extraction to concentrate the vitamin E from different raw material or in some cases, from synthetic mixtures representing the deodorizer distillate, but the extraction of sterols using supercritical fluid from the deodorizer distillate was not described in the literature.

On the other hand, due to the low content of squalene in SODD, specific extraction processes of squalene using supercritical fluid from SODD was not described in the literature. Existing studies are models of fractionation of artificial mixtures such as those mentioned above (Chang, 2000). For example, Brunner (Brunner, 1994a) studied the phase equilibrium for recovering a-tocopherol from a mixture of squalene, tocopherol, and campesterol. He concluded that the separation factor for squalene/a-tocopherol varied between a value of 4 at low squalene concentrations ( $0.5 \mathrm{wt} \%)$, to a value of 1 at high squalene concentrations ( $85 \mathrm{wt} \%$ ), at pressures ranging from 200 to $300 \mathrm{bar}$ and temperatures ranging from 70 to $100^{\circ} \mathrm{C}$.

Bondioli and coworkers (Bondioli et al., 1993) esterified FFAs into their corresponding glycerides and then applied a supercritical carbon dioxide extraction to produce a squaleneenriched fraction (purity 90.0\%, yield 91.1\%), but from olive oil deodorizer distillates.

\section{Other purification techniques}

There has been also limited literature reported on the following alternative methods for purification of tocopherols and sterols from SODD. Hence, Nagesha and coworkers (Nagesha, G. et al., 2003) using nonporous denser polymeric membranes to separate tocopherols from SODD by permeation. The separation in a denser membrane is generally based on a solution-diffusion mechanism. The lower polarity of tocopherols compared to that of free fatty acids appears to have facilitated the preferential permeation of tocopherols through the hydrophobic membrane. Selectivity of the membrane for tocopherols improved with esterified SODD, because the presence of FAME decreased the viscosity of the feed and thereby increased convective flow, which in turn improved permeate flux.

Alternatively, Maza and coworkers (Maza, 1992) concentrated tocopherols and sterols by addition of melted deodorizer distillates to a solution of urea and alcohol which separate fatty acids from the mixture.

In addition, Gunawan and coworkers (Gunawan et al., 2008a) proposed a facile procedure to isolate naturally occurring FASEs from SODD without degradation of FASEs. SODD was first subjected to a modified soxhlet extraction (MSE) to enrich FASEs in a non polar lipid fraction (NPLF). Modified silica gel column chromatography (MSE) was then applied to NPLF to collect FASEs in a third fraction with a purity of $79.99 \mathrm{wt} \%$ and a recovery of $97.38 \%$. The third fraction was then subjected to a binary solvent (water/acetone $=20 / 80$, $\mathrm{v} / \mathrm{v}$ ) extraction to purify FASEs to a purity of $86.74 \mathrm{wt} \%$ with a total recovery of $85.32 \%$. 
These methods do not present a significant advance regarding the most frequently utilized methods and probably their application to production scale would be little profitable. However, they can be used to isolate tocopherols and sterols from SODD at laboratory scale or complement other methods at industrial scale.

\section{Degradation and oxidation of functional lipids from SODD}

\subsection{Influence of refining on phytosterols}

During refining of edible fats and oils, the content of total sterols decreases due to degradation and formation of products through isomerization (D5 to D7-sterol), dehydration, polymerization, and formation of hydrocarbons or sterenes and sterol oxidation products (Dutta, 2006). These qualitative and quantitative changes in sterols can be traced in the refined oil and in by-products such as soapstocks and distillate fractions collected after chemical and physical refining processes (Dowd, 1998).

Acid hydrolysis of steryl esters may occur upon bleaching with an acid activated bleaching earth. The slight reduction of the total sterol content is due to the formation of steradienes and disteryl ethers. A gradual reduction in the total sterol content is observed at increasing deodorization temperature due to distillation and steradiene formation. Increasing the temperature from $220{ }^{\circ} \mathrm{C}$ to $260{ }^{\circ} \mathrm{C}$ resulted in a gradual reduction of the total sterol recovery from $90.4 \%$ to $67.7 \%$ in physical refining and from $93 \%$ to $62.7 \%$ in chemical refining. However in physical refining, an increase of $40 \%$ in the steryl ester fraction is observed due to an esterification reaction, promoted by high temperature between a sterol and a fatty acid. Due to the absence of free fatty acids in the chemical refining their esterification did not occur (Verleyen et al., 2001b). The influence of refining on free and esterified sterols has been studied by (Verleyen, 2002b).

Phytosterols are progressively lost during refining while continuously altering the ratio of free and esterified sterols (Kochhar, 1983). During chemical neutralization, the free sterol content is significantly reduced especially upon addition of weak caustic solution due to the loss in the soapstock (Gutfinger \& Letan, 1974).

Bleaching effects on phytosterols are generally minor and mainly limited to the formation of some nonpolar dehydration products (Ferrari, 1996) and partial hydrolysis of sterol esters (Homberg \& Bielefeld, 1982). Steradienes and disteryl ether dehydration products (Figure 1) are formed during bleaching step by the bleaching temperature and the degree of acid activation of the bleaching earth, while during the deodorization, the degree of sterol dehydration is mainly influenced by deodorization temperature giving rise to a concentration of the steradienes in the distillate (Verleyen, 2002b, Verleyen, 2001c). The presence of steradienes can also be used as a marker for the presence of refined oils (Grob et al., 1994).

Whenever applied, hydrogenation has a tremendous effect on sterol structures, including hydrogenation of double bonds, opening of cyclopropane rings, and positional isomerization of side chain unsaturation (Strocchi \& Marascio, 1993).

A part of a multinational EU research project (FOOD-CT2004-007020) was to carry out qualitative and quantitative assessment of sterols and sterol oxidation products in samples of by-products from chemical and physical refining of edible fats and oils collected from various locations in Europe. To the best of our knowledge, this is the first report on the contents of oxidized sterols in soapstock and distillate fractions from edible oil refining processes. The levels of sterol oxidation products were higher in acid oil obtained from 
chemical refining (AOCHE) samples than in acid oil obtained from physical refining (AOPHY) samples, with ranges $0.02-17.0$ and $0.01-1.5 \mathrm{mg} / 100 \mathrm{~g}$, respectively. The lower content of sterol oxidation products in AOPHY samples may be due to the high temperature applied during vacuum distillation accelerating the breakdown and transformation of the sterol oxidation products into other unidentified degradation products. Further formation of sterol oxidation products has been prevented by the high amounts of natural antioxidants in AOPHY distillate (Verleyen, 2001c). Some sterols appeared to be more liable to breakdown than others, e.g. there was a higher content of oxybrassicasterols than the other sterol oxidation products in this study, although the content of brasicasterol in the sample was lower than other sterols. Similar results have been reported previously (Dutta, 2006). This may be due to the structural arrangement in the brassicasterol molecule rendering it more easily oxidized than other sterols. However, systematic studies are required to clarify this phenomenon. Although stigmasterol has a double bond in the side-chain, similar to brassicasterol, the quantities of phytosterol oxidation products or oxyphytosterols observed in this study were quite different. Stigmasterol has an ethyl group at position C24 while brasicasterol has a methyl group, and this difference may affect in the relative rate of formation of their oxidation products (Dutta, 2006). Further studies are needed on this point.

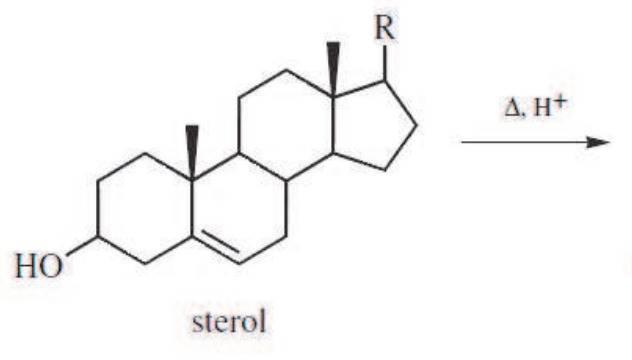<smiles></smiles>

$$
-\mathrm{H}_{2} \mathrm{O} \downarrow \Delta, \mathrm{H}^{+}
$$

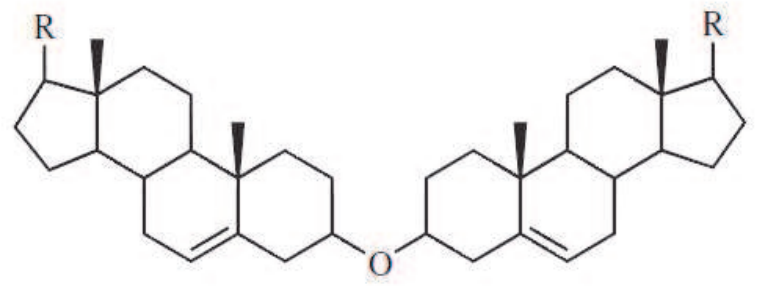

disteryl ether
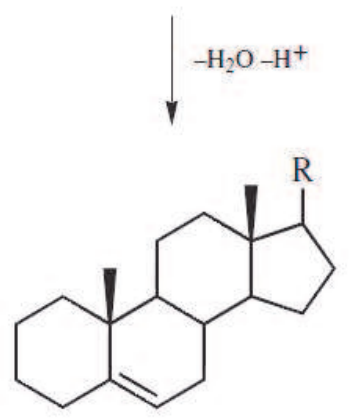

3,5 -steradiene

Fig. 1. Reaction products of sterols during refining.

It has been reported that the formation of sterol oxidation products is affected not only by the chemical nature of the sterols but also by their quantity (Dutta, 2006). There were positive correlations between total sterols and total phytosterol oxidation products in the by-products collected from both refining processes. 
The biological effects of oxycholesterol have been extensively studied (Bjorkhem et al., 2002); however, the amount of biological research on oxyphytosterols is rather scarce, mostly dated and has never been extensively reviewed before (Francesc, 2004) and (Dieter, 2004). Most reports available so far on oxyphytosterols cover the methodological aspects of their measurement in foods. The usual perception about oxyphytosterols is that these components present a concern in terms of food quality and health. This perception originates from the parallel that is made between oxycholesterol and oxyphytosterols. Whether oxyphytosterols may indeed play similar and/or different biological roles compared to oxycholesterol has not been elucidated yet.

A review (Hovenkamp et al., 2008) summarise the current knowledge on the possible biological effects of oxyphytosterols and to identify future research needs, which will help in clarifying the possible impact of oxyphytosterols on human health. The review focuses on the more common oxyphytosterols which differ only in a few structural changes from the parent sterol.

Over the last thirty years a diversity of potential biological effects, including modulation of cholesterol homeostasis, anti-inflammatory and anti-tumour activities, as well as lipidlowering and anti-diabetic properties, have been attributed to specific oxyphytosterols. Although these studies were not all carried out with oxyphytosterols also identified in the human body, these results suggest that oxyphytosterols may have systemic effects in vivo and therefore, the potential to modulate human metabolism.

Despite some putative desirable effects, oxyphytosterols may be perceived as presenting a concern in terms of food quality and health. Indeed, oxyphytosterols have been reported to exert, in vitro, cytotoxic effects comparable to those attributed to oxycholesterol. However, high, non-physiological concentrations of oxyphytosterols were needed to exert adverse effects. In addition, data from one animal study do not support a role of oxyphytosterols in atherosclerosis promotion. However, this aspect deserves more attention in future research. Altogether, the currently available observations do not suggest that oxyphytosterols, in relatively low concentrations such as those reported in human plasma, may exert in vivo deleterious effects similar to those attributed to oxycholesterol. In addition, although probably different in structure than the potentially deleterious ones, some oxyphytosterols may also have the ability to activate transcription factors involved in cholesterol metabolism. Nevertheless, more detailed investigations are needed to evaluate the biological impact of long-term exposure to physiologically relevant concentrations of oxyphytosterols in humans.

\subsection{Influence of refining on tocopherols}

During deodorization, all tocopherols present in the bleached oil will be partitioned either in the deodorized oil or in the deodorizer distillate. A significant loss in the tocopherol mass balance in the range of $25 \%-35 \%$ was observed originating from technological and/or chemical origin.

The loss of tocopherols can be caused either by a thermal breakdown at temperatures higher than $240{ }^{\circ} \mathrm{C}$, by oxidation reaction or by chemical reaction such as the formation of tocopheryl esters (Verleyen et al., 2001a). Extensive analysis of vegetable oils by HPLC and comparison with synthesized tocopheryl esters did not show any adsorption in the elution region of tocopheryl esters, indicating that esters of tocopherols with fatty acids are not present in crude oils (Verleyen, 2001c). Therefore the stability of tocopherols during 
deodorization has been studied under various process conditions. The presence of oxidation products has no influence on the loss of tocopherols during deodorization based on the fact that two successive deodorization steps yielded identical loss of tocopherols.

Experiments using spiked triolein with 2000 ppm of a-tocopherol showed that the addition of tertbutylhydroquinone (TBHQ) as a strong antioxidant reduces the loss of tocopherols with more than $50 \%$ in comparison with the reference procedure. a- Tocopherol (2000 ppm) was dissolved in triolein and heated to $254^{\circ} \mathrm{C}, 5-6 \mathrm{mbar}$, for $80 \mathrm{~min}$, with no steam injection. $9 \%$ of tocopherol loss was observed in the control sample and 3\% for the sample with 1500 ppm TBHQ. The more active TBHQ will compete with tocopherols to scavenge radicals and consequently the tocopherol loss in the mass balance is reduced as more natural tocopherols stay in the oil or in the distillate (Verleyen et al., 2002a, Verleyen et al., 2003).

In vegetable oils, the addition of TBHQ from 0 to $1500 \mathrm{ppm}$ establishes a gradual reduction in tocopherol loss from $26.7 \%$ to $17.6 \%$ while the concentration of tocopherols in the distillate rises from $1.85 \%$ to $2.35 \%$. Performing deodorization with nitrogen as stripping agent showed an important reduction in the tocopherol loss (Verleyen, 2002a). In the model study with triolein no reduction of a-tocopherol was observed while using corn oil a reduction of $30 \%-50 \%$ was observed. The highest reduction was detected at severe deodorization conditions $\left(260^{\circ} \mathrm{C}, 3 \mathrm{mbar}\right)$ (Verleyen, 2002a). These experiments show that tocopherols are thermally stable compounds and probably the loss of tocopherols is due to oxidation reactions, which leads to compounds such as a- tocopherol dimer quinone, 4a, 5epoxytocopherolquinone, 7, 8-epoxy tocopherol quinone, tocopherol dimer quinone, tocopherol spirotrimer and ditocopherol ethers (Verleyen, 2001a). These compounds can be found in the finished oil and in the distillate.

In a model experiment using $3500 \mathrm{ppm}$ a- tocopherol in triolein and heating at $240{ }^{\circ} \mathrm{C}$ for 90 $\min$ at a reduced pressure of 6-7 mbar 4a, 5-epoxytocopherolquinone, 7, 8-epoxy tocopherolquinone and a-tocopherol quinone were identified as oxidation products supporting that the tocopherol loss during deodorization is mainly due to oxidative degradation (Verleyen, 2002a).

\section{Nonfood applications}

As commented previously, soybean deodorizer distillate represent good source of valuable compounds such as phytosterols, tocopherols and squalene, which can be recovered and further used as food additives, in pharmaceutical industry and cosmetics. Alternatively, deodorizer distillates have nonfood applications, such as biodiesel or can be used mixed with the fuel oil to fire the steam boilers (Svensson, 1976).

Refined vegetable oils are the predominant feedstocks used for the production of biodiesel. However, their relatively high cost renders the resulting fuels unable to compete with petroleum-derived fuel and makes the use of side-stream refining products (soapstock, acid oil and deodorizer distillate) important alternatives as a feedstock for biodiesel production.

Biodiesel is produced from deodorizer distillates by direct esterification of the FFA or by conversion of FFA to acylglycerols prior transesterification (Figure 2). Esterification of the FFA is also performed as a preliminary step in the purification of the tocopherols and sterols in order to reduce their boiling points, thereby facilitating their separation. 

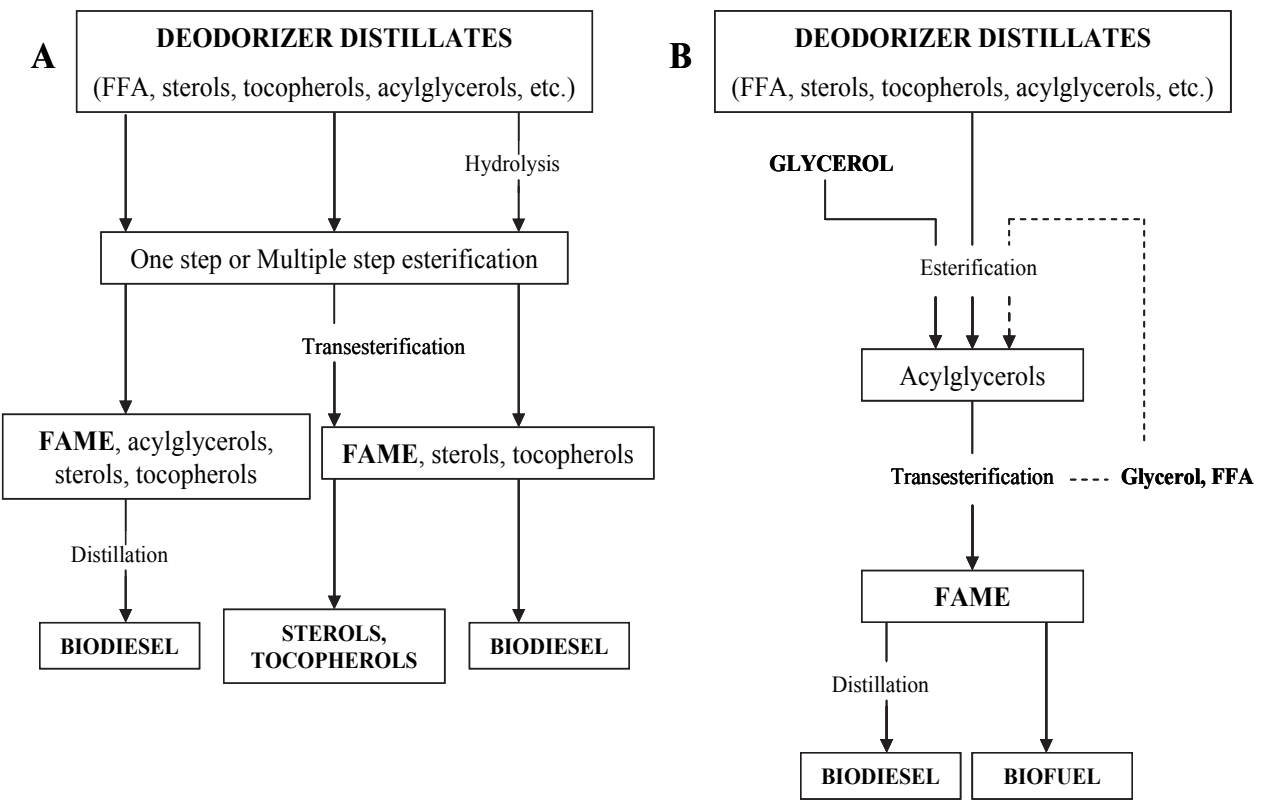

Fig. 2. Production of biodiesel from deodorizer distillates by direct conversion (A) and via acylglycerols route (B).

\subsection{Production of biodiesel by direct conversion 9.1.1 Chemically catalyzed process}

Verhé and coworkers (Verhé et al., 2008) reported a process of converting the deodorizer distillates to biodiesel using methanol in a weight ratio 1:1 and $5 \% \mathrm{w} / \mathrm{w}$ sulphuric acid as catalyst, at $75{ }^{\circ} \mathrm{C}$ for $5 \mathrm{~h}$. Under the mentioned conditions, the FFA have undergone esterification while MAG reacted via transesterification, resulting in methyl esters. The crude biodiesel was further washed with $20 \%$ water for $15 \mathrm{~min}$, dried and distilled in order to increase the quality of the methyl esters. The distillation pitch was further processed for the recovery of sterols and tocopherols.

Facioli and Arellano (Facioli \& Barrera-Arellano, 2002) described a process to obtain ethyl esters from SODD. SODD contained $47.5 \%$ FFA C18:1, $26.2 \%$ acylglycerols and $26.2 \%$ unsaponifiable matter using concentrated sulphuric acid as catalyst. The optimum conditions found in this study were for EtOH:FFA between 6.4:1 to 11.2:1, $\mathrm{H}_{2} \mathrm{SO}_{4}$ from 0.9$1.5 \%$ and reaction time from $1.3 \mathrm{~h}$ to $2.6 \mathrm{~h}$. Under the described conditions a conversion of $94 \%$ of the fatty acids to ethyl esters was achieved. Tocopherols losses were below $5.5 \%$. A molar excess of ethanol in relation to SODD:FFA was found to be necessary to obtain the best conversion.

Hammond and coworkers (Hammond \& Tong, 2005) described a three-stage acid catalyzed esterification using a molar ratio acid oil:methanol:sulphuric acid of 1:1.3:0.03 for the first stage $(25 \mathrm{~h})$. The reaction mixture was centrifuged, the supernatant lipid phase was separated from the sludge (glycerol, water, acid and methanol), and further reacted with methanol and acid, keeping the previous mentioned ratios of unreacted lipid:methanol:sulphuric acid. 
It was seen that the reaction proceeded rapidly during the first hour of reaction and then slowed down considerably. In contrast, the second and third stage showed a gradual increase in FAME over time. The maximum FAME conversion obtained for 12 tested acid oils averaged $81 \%$. However, the ester phase could not be increased above $85 \%$ even after a fourth-stage reaction or if a base catalyst (sodium methoxide) was used in large excess. If higher amount of methanol was used, the initial reaction tended to go faster, but the reaction reached the plateau in a short time. Furthermore, an increase in the acid catalyst concentration above $1.2 \%$ did not affect the initial reaction rate.

\subsubsection{Enzymatically catalyzed process}

Several enzymatic methods have been developed for the conversion of fatty acids into FAMEs or FAEEs with positive results. One of the main disadvantages of use of biocatalysts is the high price compared to chemical catalyst, although unfortunately, no rigorous economical viability of these enzymatic procedures has been reported.

Facioli and Arellano (Facioli \& Barrera-Arellano, 2001) investigated the enzymatic esterification of the free fatty acids from SODD with ethanol using immobilized fungal lipase (Lipozyme IM) as biocatalyst. SODD contained $47.5 \%$ FFA, $26.22 \%$ neutral oil and $26.23 \%$ unsaponifiable matter. The effect of three independent variables: temperature, enzyme concentration and EtOH:FFA molar ratio on the conversion rate of FFA to ethyl esters was studied. The best conversion (above $88 \%$ ) was obtained with EtOH:FFA ratio 1.7$3.2: 1$, temperature in the range $46.4{ }^{\circ} \mathrm{C}$ to $53.6{ }^{\circ} \mathrm{C}$, lipase concentration from 10.7 to $23.0 \%$ and the reaction time of $2 \mathrm{~h}$. All three variables had statistically significant effect on the conversion of the FFAs to ethyl esters. During the above mentioned esterification process no tocopherols losses were observed.

The esterification of SODD with butanol using Mucor miehei lipase as a biocatalyst and supercritical carbon dioxide $\left(\mathrm{SC}-\mathrm{CO}_{2}\right)$ has been described by Nagesha and coworkers (Nagesha, 2004). The SODD contained $56.0 \%$ neutral oil, $25.3 \%$ FFA, $7.2 \%$ sterols, $2.9 \%$ tocopherols, $0.6 \%$ hydrocarbons and $0.13 \%$ moisture. It was preliminary filtered in order to remove sediments and sterols and enzymatic hydrolyzed to free fatty acid using immobilized lipase (Candida rugosa) in $\mathrm{SC}-\mathrm{CO}_{2}$ reactor unit. The operational conditions were as follows: pressure 160 bar, temperature $45^{\circ} \mathrm{C}$, moisture content $60 \%(\mathrm{w} / \mathrm{w})$ and enzyme concentration $200 \mathrm{U} / \mathrm{g}$ of SODD. Hydrolyzed SODD containing $87.8 \%$ (w/w) FFA was further esterified for $3 \mathrm{~h}$ in presence of butanol (1.2 M) using $15 \%$ enzyme (w/w) (M. miehei), pressure 120 bar and temperature $35^{\circ} \mathrm{C}$. The maximum yield of $95 \%$ FABE was achieved.

The high content of residual glycerides $(3.10 \%)$ present in the final FABE precluded its direct use as biodiesel. However, the process was designed as preliminary step for the purification of tocopherols, since hydrolysis/esterification helps their recovery.

Wang and coworkers (Wang et al., 2006) described a process for simultaneously conversion of FFA (28\%) and acylglycerols $(60 \%)$ from SODD to alkyl esters using a mixture of two enzymes (3 \% Lipozyme TL IM and $2 \%$ Novozym 435) in the presence of tert-butanol as cosolvent. It was found that the negative effects on the enzyme stability caused by the excessive methanol ratio and by-product glycerol could be minimized by using tert-butanol. The lipase activity remained stable after 120 cycles. The maximum yield of FAME (84 \%) was achieved with an increase of tert-butanol content up to $80 \%$ (based on the oil weight). However, a further increase of the solvent resulted in a decrease of the FAME yield which was explained by the dilution effect on reactants. 
$\mathrm{Du}$ and coworkers (Du et al., 2007) investigated the enzymatic esterification of SODD containing $28 \%$ FFA, $60 \%$ TAG and $6 \%$ tocopherols. The reaction was lipase mediated methanolysis using Novozym 435 as catalyst, at $40{ }^{\circ} \mathrm{C}$ in a solvent free medium. The enzyme kept its activity after being reused for 10 cycles, each cycle of $24 \mathrm{~h}$. The highest biodiesel yield of $95 \%$ was achieved by adding 10 fold of $3 \AA$ molecular sieves (based on the maximum water produced from FFA esterification). The investigation of the lipase to methanol tolerance revealed that the lipase could maintain its stability and activity in the presence of even 3 molar concentration of methanol. This tolerance was attributed to the presence of other compounds apart from triglycerides, namely FFA, sterols and tocopherols. A linear relationship between the FFA content and the lipase tolerance to methanol was observed but the presence of sterols and tocopherols showed no effect. The correlation between the initial FFA present in the feedstock and the rate of conversion was confirmed by other authors (Hammond \& Tong, 2005).

\subsection{Production of biodiesel via acylglycerols route}

Another approach reported in the literature consists on esterification of FFA with glycerol to form acylglycerols, followed by conventional transesterification. Synthesis of MAG from deodorizer distillate was mainly studied due to the large number of applications as additives (e.g. enhancing plasticity of fats) in the food, medicine and cosmetic industry. Among synthesized acylglycerols, the monoester has the highest surface activity and therefore, its concentration is very important for direct utilization of the reaction mixture as emulsifier.

Although the use of a large number of different heterogeneous catalysts have been reported in literature, most of the research has been done on the synthetic samples and less on the side stream refining products. Different studies summarized hereunder describe processes for synthesis of acylglycerols as an intermediate step in the production of biodiesel/biofuels. These processes are catalyzed either chemically or enzymatically, or conducted under noncatalytic conditions.

\subsubsection{Enzymatically catalyzed process}

Tangkam and coworkers (Tangkam et al., 2008) described the enzymatic esterification in a solvent free medium of different deodorizer distillates resulting from the refining of various vegetable oils. A direct esterification of mixed distillates (61 \% FFA and $39 \%$ acylglycerols) with glycerol using immobilized lipase B from Candida Antarctica (Novozym 435) led to moderate proportions (46\%) of DAG. Application of a two-stage reaction consisting of a hydrolysis step of deodorizer distillate to increase the FFA content followed by esterification with glycerol led to a higher formation ( $>61 \%$ ) of DAG. Furthermore, it was observed that the high initial concentration of free fatty acids in the distillate has a positive influence on the concentration of DAG in the final product $(>71 \%)$. This observation is consistent with other literature data (Yamada et al., 1999). Enrichment of DAG in the final products by shortpath vacuum distillation led to concentrates containing up to $94 \%$ DAG, $5 \%$ TAG and no unesterified fatty acids and MAG.

\subsubsection{Non-catalytic process}

Smet (Smet, 2008) described a process for the esterification of fatty acid distillate (93\% FFA) with technical grade glycerol. The reaction was carried out in a high pressure Parr reactor 
(stirred and thermostated reactor of stainless steal). The following parameters have been checked: temperature, reactor design, agitation speed, molar ratio and influence of the catalyst. The best results were obtained at $200{ }^{\circ} \mathrm{C}$, pressure of $90 \mathrm{mbar}$ and agitation speed of $60 \mathrm{rpm}$. It was seen that by using a molar ratio 1:1 FFA:glycerol, a total glycerides content of $85.3 \%$ was obtained within 345 min reaction time. The formation of MAG was faster in the first hours and than reached the plateau, while the formation of DAG was slower at the beginning of the reaction and faster at the end. Furthermore, an increase in the molar ratio of 1:2 FFA:glycerol slow down the reaction, the total glycerides content reaching $64.9 \%$ within 345 min reaction time. A molar ratio 2:1 FFA:glycerol gave an increase of the MAG and DAG at the beginning of the reaction, followed by an decrease of MAG after $90 \mathrm{~min}$, the glycerol being completely consumed in within $345 \mathrm{~min}$ reaction time. The percent of DAG and TAG increased gradually during reaction, reaching a final yield of $86.2 \%$ of total acylglycerols.

However the FFA content was still high, a distillation step of the residual FFAs and glycerol was necessary in order to increase the purity of the synthesized acylglycerols. The byproducts of distillation were further re-used as reaction products in the synthesis of acylglycerols. The novelty of the process consists in synthesizing acylglycerols in a relatively short time $(<6 \mathrm{~h})$ in a catalyst free medium.

\section{Concluding remarks}

Deodorizer distillate is an excellent source of valuable compounds such as phytosterols and tocopherols. Numerous procedures have been described to isolate bioactive compounds from soybean oil deodorizer distillates to improve the value and the quality of this byproduct. All these procedures can be grouped in four generic categories: classic methods such as crystallization and precipitation, chemical and enzymatic modification, molecular distillation, and supercritical fluid extraction.

Crystallization seems successful as a simple and efficient process to remove and concentrate sterols and tocopherols from SODD. However solvent based processes are expensive, unattractive and less environmentally friendly, resulting in a scarce and expensive final product.

To increase the separation efficiency of the compounds of interest from SODD, esterification and/or transesterification reactions are usually carried out prior to the purification or fractionation procedure. Hence, the utilization of enzymes, for instance, makes easier the separation of tocopherols from SODD by converting sterols to steryl esters, acylglycerols to free fatty acids and free fatty acids to fatty acid methyl or ethyl esters (FAMEs or FAEEs). Then, it is easier to separate the new product mixture by distillation or supercritical fluid extraction. The main difficulties of the enzymatic processes are the numerous parameters involved such as moisture content, enzyme concentration, time, temperature, ratio of the reactants, stability, recovery and reutilization of the enzyme preparation, among others. However, it is possible to separate the sterol esterification and ethyl esterification in time or space to optimize each of these reactions independently, thereby minimizing costs or improving the yield of the desired final reaction products.

Among the great variety of processes that have been patented for the purification of the compounds of the SODD, only the processes of esterification of fatty acids and acylglycerols with methanol or ethanol followed by high vacuum distillation, have been developed on a commercial scale for the concentration of tocopherols 
Regarding supercritical fluid fractionation SODD is not adequate feed material to work with $\mathrm{SC}-\mathrm{CO}_{2}$ for tocopherol enrichment, owing to its poor $\mathrm{SC}-\mathrm{CO}_{2}$ solubility. So, to concentrate tocopherols from SODD, pre-treatment of the raw material is needed to obtain the primary tocopherols concentrate with improve solubility in $\mathrm{SC}-\mathrm{CO}_{2}$.

Alternatively, deodorizer distillates have also non-food applications, such as biodiesel or can be used mixed with the fuel oil to fire the steam boilers. The use of deodorizer distillate instead of refined vegetable oils is an important alternative as a feedstock for biodiesel production.

Two main degradation products from sterols can be observed in SODD, namely dehydration and oxidation products. The degree of sterol dehydration is mainly influenced by deodorization temperature giving rise to a variable concentration of steradienes in the distillate. The content of oxidized sterols in deodorization distillate fractions from edible oil refining processes fluctuates depending on both the temperature applied during vacuum distillation and the breakdown and transformation of oxidized sterols into other unidentified degradation products. Finally, formation of oxidized sterols can be partially prevented by the high amounts of natural antioxidants in acid oil obtained from physical refining distillate. The current knowledge on the possible biological effects of oxyphytosterols is limited and further research to clarify the possible impact of oxyphytosterols on human health is needed.

\section{References}

Andrews, J. S. (1941). Process for preparation of vitamin e concentrate and antioxidant. U. S. Patent 2.263.550.

Awad, A. B., Roy, R., \& Fink, C. S. (2003). Beta-sitosterol, a plant sterol, induces apoptosis and activates key caspases in MDA-MB-231 human breast cancer cells. Oncol Rep. Vol. 10, No. 2, pp. 497-500.

Balazs, I. (1987). Refining and use of byproducts from various fats and oils. Journal of the American Oil Chemists' Society. Vol. 64, No. 8, pp. 1126-1128.

Batistella, C. B., Moraes, E. B., Maciel Filho, R., \& Maciel, M. R. (2002). Molecular distillation: rigorous modeling and simulation for recovering vitamin $\mathrm{E}$ from vegetal oils. Appl. Biochem. Biotechnol. Vol. 98-100, No. pp. 1187-206.

Batistella, C. B. \& Wolf Maciel, M. R. (1998). Recovery of carotenoids from palm oil by molecular distillation. Computers \& Chemical Engineering. Vol. 22, No. Supplement 1, pp. S53-S60.

Bjorkhem, I., Meaney, S., \& Diczfalusy, U. (2002). Oxysterols in human circulation: which role do they have? Current Opinion in Lipidology. Vol. 13, No. 3, pp. 247-253.

Block, G. \& Langseth, L. (1994). Antioxidant vitamins and disease prevention. Food Technology. Vol. 48, No. 7, pp. 80-84.

Bockisch, M. (1998). Fats and oils handbook. (AOCS, Champaign, IL.

Bondioli, P., Mariani, C., Lanzani, A., Fedeli, E., \& Muller, A. (1993). Squalene recovery from olive oil deodorizer distillates. Journal of the American Oil Chemists' Society. Vol. 70, No. 8, pp. 763-766. 
Bouic, P. J. D. (2001). The role of phytosterols and phytosterolins in immune modulation: a review of the past 10 years. Current Opinion in Clinical Nutrition \& Metabolic Care. Vol. 4, No. 6, pp. 471-475.

Breivik, H., Haraldsson, G., \& Kristinsson, B. (1997). Preparation of highly purified concentrates of eicosapentaenoic acid and docosahexaenoic acid. Journal of the American Oil Chemists' Society. Vol. 74, No. 11, pp. 1425-1429.

Brown, W. \& Meag, K. H. (1963). Process for recovery of tocopherols and sterols. U.S. Patent $3,108,120$.

Brown, W. \& Smith, F. E. (1964). Process for separating tocopherols and sterols from deodorizer sludge and the like. U.S. Patent 3,153,055.

Brunner, G. (1994a). Gas Extraction. Springer: New York.

Brunner, G. (1994b). Gas Extraction-An Introduction to Fundamentals of Supercritical Fluid and the Application to Separation Processes. Springer, Berlin

Brunner, G., Malchow, T., Stürken, K., \& Gottschau, T. (1991). Separation of tocopherols from deodorizer condensates by countercurrent extraction with carbon dioxide. The Journal of Supercritical Fluids. Vol. 4, No. 1, pp. 72-80.

Buczenko, G. M., de Oliveira, J. S., \& von Meien, O. F. (2003). Extraction of tocopherols from the deodorized distillate of soybean oil with liquefied petroleum gas. European Journal of Lipid Science and Technology. Vol. 105, No. 11, pp. 668-671.

Cvengros, J., Lutisan, J., \& Micov, M. (2000). Feed temperature influence on the efficiency of a molecular evaporator. Chemical Engineering Journal. Vol. 78, No. 1, pp. 61-67.

Czuppon, T., Kemeny, Z., Kovari, E., \& Recseg, K. (2003). Process for recovery of plant sterols from by-product of vegetable oil refining. WO2004000979.

Chang, C. J., Chang, Y.-F., Lee, H.-z., Lin, J.-q., \& Yang, P.-W. (2000). Supercritical Carbon Dioxide Extraction of High-Value Substances from Soybean Oil Deodorizer Distillate. Industrial \& Engineering Chemistry Research. Vol. 39, No. 12, pp. 45214525 .

Chu, B. S., Baharin, B. S., \& Quek, S. Y. (2002). Factors affecting pre-concentration of tocopherols and tocotrienols from palm fatty acid distillate by lipase-catalysed hydrolysis. Food Chemistry. Vol. 79, No. 1, pp. 55-59.

de Jong, A., Plat, J., \& Mensink, R. P. (2003). Metabolic effects of plant sterols and stanols (Review). The Journal of Nutritional Biochemistry. Vol. 14, No. 7, pp. 362-369.

de Lucas, A., Martinez de la Ossa, E., Rincón, J., Blanco, M. A., \& Gracia, I. (2002). Supercritical fluid extraction of tocopherol concentrates from olive tree leaves. The Journal of Supercritical Fluids. Vol. 22, No. 3, pp. 221-228.

Dieter, L. (2004). Sterol autoxidation: from phytosterols to oxyphytosterols. British Journal of Nutrition. Vol. 91, No. pp. 3-4.

Donova, M. (2007). Transformation of steroids by actinobacteria: A review. Applied Biochemistry and Microbiology. Vol. 43, No. 1, pp. 1-14.

Dowd, M. K. (1998). Gas chromatographic characterization of soapstocks from vegetable oil refining. Journal of Chromatography A. Vol. 816, No. 2, pp. 185-193.

Du, W., Wang, L., \& Liu, D. (2007). Improved methanol tolerance during Novozym435mediated methanolysis of SODD for biodiesel production. Green Chemistry. Vol. 9, No. 2, pp. 173-176. 
Dumont, M.-J. \& Narine, S. S. (2007). Soapstock and deodorizer distillates from North American vegetable oils: Review on their characterization, extraction and utilization. Food Research International. Vol. 40, No. 8, pp. 957-974.

Dutta, P. C., Przybylski, R., \& Eskin, M. (2006). Formation, analysis and health effects of oxidized sterols in frying fat, In: Deep frying: chemistry, nutrition and practical applications, M. D. Erickson, Editor, pp. 111-164, AOCS Press, Urbana, IL.

Facioli, N. \& Barrera-Arellano, D. (2002). Optimization of direct acid esterification process of soybean oil deodorizer distillate. Grasas y Aceites. Vol. 53, No. 2, pp. 206-212.

Facioli, N. L. \& Barrera-Arellano, D. (2001). Optimisation of enzymatic esterification of soybean oil deodoriser distillate. Journal of the Science of Food and Agriculture. Vol. 81, No. 12, pp. 1193-1198.

Fang, T., Goto, M., Sasaki, M., \& Hirose, T. (2005). Phase Equilibria for the Ternary System Methyl Oleate + Tocopherol + Supercritical $\mathrm{CO}_{2}$. Journal of Chemical E Engineering Data. Vol. 50, No. 2, pp. 390-397.

Fang, T., Goto, M., Wang, X., Ding, X., Geng, J., Sasaki, M., \& Hirose, T. (2007). Separation of natural tocopherols from soybean oil byproduct with supercritical carbon dioxide. The Journal of Supercritical Fluids. Vol. 40, No. 1, pp. 50-58.

Fernandes, P. \& Cabral, J. M. S. (2007). Phytosterols: Applications and recovery methods. Bioresource Technology. Vol. 98, No. 12, pp. 2335-2350.

Ferrari, R., Schulte, E., Esteves, W., Brühl, L., \& Mukherjee, K. (1996). Minor constituents of vegetable oils during industrial processing. Journal of the American Oil Chemists' Society. Vol. 73, No. 5, pp. 587-592.

Fizet, C. (1996). Process for tocopherols and sterols from natural sources. U.S. Patent $5,487,817$.

Francesc, G. (2004). Phytosterol oxidation products: state of the art. Reprod. Nutr. Dev. Vol. 44, No. 6, pp. 597-598.

Gangopadhyay, S., Nandi, S., \& Ghosh, S. (2007). Biooxidation of Fatty Acid Distillates to Dibasic Acids by a Mutant of Candida tropicalis. Journal of Oleo Science. Vol. 56, No. 1, pp. 13-17.

Gapor, A., Leong, L. W., \& Ong, A. (1989). Production ofhigh concentration tocopherols and tocotrienols from palm oil by-products. European Patent Application 0,3 33,472442.

Gast, K., Jungfer, M., Saure, C., \& Brunner, G. (2005). Purification of tocochromanols from edible oil. The Journal of Supercritical Fluids. Vol. 34, No. 1, pp. 17-25.

Gavin, A. (1978). Edible oil deodorization. Journal of the American Oil Chemists' Society. Vol. 55, No. 11, pp. 783-791.

Ghosh, S. \& Bhattacharyya, D. (1996). Isolation of tocopherol and sterol concentrate from sunflower oil deodorizer distillate. Journal of the American Oil Chemists' Society. Vol. 73, No. 10, pp. 1271-1274.

Grob, K., Biedermann, M., Bronz, M., \& Giuffré, A. M. (1994). The Detection of Adulteration with Desterolized Oils. Lipid / Fett. Vol. 96, No. 9, pp. 341-345.

Gunawan, S., Ismadji, S., \& Ju, Y.-H. (2008a). Design and operation of a modified silica gel column chromatography. Journal of the Chinese Institute of Chemical Engineers. Vol. 39, No. 6, pp. 625-633. 
Gunawan, S., Kasim, N. S., \& Ju, Y.-H. (2008b). Separation and purification of squalene from soybean oil deodorizer distillate. Separation and Purification Technology. Vol. 60, No. 2, pp. 128-135.

Gutfinger, T. \& Letan, A. (1974). Quantitative changes in some unsaponifiable components of soya bean oil due to refining. Journal of the Science of Food and Agriculture. Vol. 25, No. 9, pp. 1143-1147.

Hammond, E. G. \& Tong, W. (2005). Method of converting free fatty acids to fatty acid methyl esters with small excess of methanol. U.S. Patent 6965044.

Haraldsson, G. (1992). The application of lipases in organic synthesis. (John Wiley,

Hedström, G., Slotte, J. P., Backlund, M., Molander, O., \& Rosenholm, J. B. (1992). LipaseCatalyzed Synthesis and Hydrolysis of Cholesterol Oleate in Aot/Isooctane Microemulsions. Biocatalysis and Biotransformation. Vol. 6, No. 4, pp. 281 - 290.

Hickman, K. C. D. (1944). Purification of sludges, scums, and the like to prepare relatively purified tocopherol. U. S. Patent 2.349.270

Hirota, Y., Nagao, T., Watanabe, Y., Suenaga, M., Nakai, S., Kitano, A., Sugihara, A., \& Shimada, Y. (2003). Purification of steryl esters from soybean oil deodorizer distillate. Journal of the American Oil Chemists' Society. Vol. 80, No. 4, pp. 341-346.

Homberg, E. \& Bielefeld, B. (1982). Free and bound sterols in crude and refined palm oils. . Fette Seifen Anstrichm. Vol. 84, No. pp. 141-146.

Hovenkamp, E., Demonty, I., Plat, J., Lütjohann, D., Mensink, R. P., \& Trautwein, E. A. (2008). Biological effects of oxidized phytosterols: A review of the current knowledge. Progress in Lipid Research. Vol. 47, No. 1, pp. 37-49.

Hunt, T. K., Jeromin, L., Johannisbauer, W., Gutsche, B., Jordon, V., \& Wogatzki, H. (1997). Recovery of tocopherols. U.S. Patent 5,646,311.

Ito, V., Martins, P., Batistella, C., Filho, R., \& Wolf Maciel, M. (2006). Natural compounds obtained through centrifugal molecular distillation. Applied Biochemistry and Biotechnology. Vol. 131, No. 1, pp. 716-726.

Jacobs, L. (2005). Process for the Production of Tocotrienols. U.S. Patent 6,838,104.

Jonzo, M. D., Hiol, A., Druet, D., \& Comeau, L. C. (1997). Application of Immobilized Lipase from Candida rugosa to Synthesis of Cholesterol Oleate. Journal of Chemical Technology \& Biotechnology. Vol. 69, No. 4, pp. 463-469.

Jung, M., Yoon, S., \& Min, D. (1989). Effects of processing steps on the contents of minor compounds and oxidation of soybean oil. Journal of the American Oil Chemists' Society. Vol. 66, No. 1, pp. 118-120.

Jung, M. Y. \& Min, D. B. (1990). Effects of $\alpha^{-}, \mathrm{Y}^{-}$, and $\delta$-Tocopherols on Oxidative Stability of Soybean Oil. Journal of Food Science. Vol. 55, No. 5, pp. 1464-1465.

Kasim, N. S., Gunawan, S., \& Ju, Y.-H. (2009). Isolation and identification of steroidal hydrocarbons in soybean oil deodorizer distillate. Food Chemistry. Vol. 117, No. 1, pp. 15-19.

Khatoon, S., Raja Rajan, R., \& Gopala Krishna, A. (2010). Physicochemical Characteristics and Composition of Indian Soybean Oil Deodorizer Distillate and the Recovery of Phytosterols. Journal of the American Oil Chemists' Society. Vol. 87, No. 3, pp. 321326. 
Kijima, S., Ichikana, N., \& Naito, K. (1964). Purification process of tocopherol containing materials. U.S. Patent 3,122,565.

Kim, S. K. \& Rhee, J. S. (1982). Isolation and purification of tocopherols and sterols from distillates of soy oil deodorization. Kor. J. Food Sci. Technol. Vol. 14, No. pp. 174178.

King, J. W., Favati, F., \& Taylor, S. L. (1996). Production of Tocopherol Concentrates by Supercritical Fluid Extraction and Chromatography. Separation Science and Technology. Vol. 31, No. 13, pp. 1843 - 1857.

Kline, K., Lawson, K. A., Yu, W., \& Sanders, B. G. (2007). Vitamin E and Cancer, in Vitamins and Hormones. pp. 435-461.

Kochhar, S. P. (1983). Influence of processing on sterols of edible vegetable oils. Progress in Lipid Research. Vol. 22, No. 3, pp. 161-188.

Kritchevsky, D. \& Chen, S. C. (2005). Phytosterols--health benefits and potential concerns: a review. Nutrition Research. Vol. 25, No. 5, pp. 413-428.

Lee, H., Chung, B., \& Park, Y. (1991). Concentration of tocopherols from soybean sludge by supercritical carbon dioxide. Journal of the American Oil Chemists' Society. Vol. 68, No. 8, pp. 571-573.

Lin, K.-M. \& Koseoglu, S. S. (2003). Separation of sterols from deodorizer distillate by crystallization. Journal of Food Lipids. Vol. 10, No. 2, pp. 107-127.

Lin, K.-M., Zhang, X., \& Koseoglu, S. S. (2004). Separation of tocopherol succinates from deodorizer distillate. Journal of Food Lipids. Vol. 11, No. 1, pp. 29-43.

Lin, K. M. (2002). National Chung Hsing University, M.S., Texas A\& M University. No.

Lutisan, J., Cvengros, J., \& Micov, M. (2002). Heat and mass transfer in the evaporating film of a molecular evaporator. Chemical Engineering Journal. Vol. 85, No. 2-3, pp. 225234.

Marangoni, A. G. \& Rousseau, D. (1995). Engineering triacylglycerols: The role of interesterification. Trends in Food Science \& Technology. Vol. 6, No. 10, pp. 329335.

Martins, P. F., Batistella, C. s. B., Maciel-Filho, R., \& Wolf-Maciel, M. R. (2005). Comparison of Two Different Strategies for Tocopherols Enrichment Using a Molecular Distillation Process. Industrial \& Engineering Chemistry Research. Vol. 45, No. 2, pp. 753-758.

Martins, P. F., Ito, V. M., Batistella, C. B., \& Maciel, M. R. W. (2006). Free fatty acid separation from vegetable oil deodorizer distillate using molecular distillation process. Separation and Purification Technology. Vol. 48, No. 1, pp. 78-84.

Maza, A. (1992). Process for separating mixed fatty acids from deodorant distillate using urea. U.S. Patent 5078920.

Mendes, M. F., Pessoa, F. L. P., Coelho, G. V., \& Uller, A. M. C. (2005). Recovery of the high aggregated compounds present in the deodorizer distillate of the vegetable oils using supercritical fluids. The Journal of Supercritical Fluids. Vol. 34, No. 2, pp. 157162.

Mendes, M. F., Pessoa, F. L. P., \& Uller, A. M. C. (2002). An economic evaluation based on an experimental study of the vitamin E concentration present in deodorizer distillate 
of soybean oil using supercritical $\mathrm{CO}_{2}$. The Journal of Supercritical Fluids. Vol. 23, No. 3, pp. 257-265.

Mendes, M. F., Uller, A. M. C., \& Pessoa, F. L. P. (2000). Simulation and thermodynamic modeling of the extraction of tocopherol from a synthetic mixture of tocopherol, squalene and $\mathrm{CO}_{2}$. Brazilian Journal of Chemical Engineering. Vol. 17, No. pp. 761770 .

Moghadasian, M. H., McManus, B. M., Godin, D. V., Rodrigues, B., \& Frohlich, J. J. (1999). Proatherogenic and Antiatherogenic Effects of Probucol and Phytosterols in Apolipoprotein E-Deficient Mice : Possible Mechanisms of Action. Circulation. Vol. 99, No. 13, pp. 1733-1739.

Moghadasian, M. H., McManus, B. M., Pritchard, P. H., \& Frohlich, J. J. (1997). "Tall Oil"Derived Phytosterols Reduce Atherosclerosis in ApoE-Deficient Mice. Arterioscler Thromb Vasc Biol. Vol. 17, No. 1, pp. 119-126.

Moreira, E. \& Baltanás, M. (2004). Recovery of phytosterols from sunflower oil deodorizer distillates. Journal of the American Oil Chemists' Society. Vol. 81, No. 2, pp. 161167.

Mulligan, J. D., Flowers, M. T., Tebon, A., Bitgood, J. J., Wellington, C., Hayden, M. R., \& Attie, A. D. (2003). ABCA1 Is Essential for Efficient Basolateral Cholesterol Efflux during the Absorption of Dietary Cholesterol in Chickens. Journal of Biological Chemistry. Vol. 278, No. 15, pp. 13356-13366.

Munteanu, A. \& Zingg, J. M. (2007). Cellular, molecular and clinical aspects of vitamin E on atherosclerosis prevention. Molecular Aspects of Medicine. Vol. 28, No. 5-6, pp. 538590.

Nagao, T., Kobayashi, T., Hirota, Y., Kitano, M., Kishimoto, N., Fujita, T., Watanabe, Y., \& Shimada, Y. (2005). Improvement of a process for purification of tocopherols and sterols from soybean oil deodorizer distillate. Journal of Molecular Catalysis B: Enzymatic. Vol. 37, No. 1-6, pp. 56-62.

Nagesha, G., Subramanian, R., \& Sankar, K. (2003). Processing of tocopherol and FA systems using a nonporous denser polymeric membrane. Journal of the American Oil Chemists' Society. Vol. 80, No. 4, pp. 397-402.

Nagesha, G. K., Manohar, B., \& Udaya Sankar, K. (2003). Enrichment of tocopherols in modified soy deodorizer distillate using supercritical carbon dioxide extraction. European Food Research and Technology. Vol. 217, No. 5, pp. 427-433.

Nagesha, G. K., Manohar, B., \& Udaya Sankar, K. (2004). Enzymatic esterification of free fatty acids of hydrolyzed soy deodorizer distillate in supercritical carbon dioxide. The Journal of Supercritical Fluids. Vol. 32, No. 1-3, pp. 137-145.

Nergiz, C. \& Çelikkale, D. (2010). The effect of consecutive steps of refining on squalene content of vegetable oils. Journal of Food Science and Technology. Vol. No. pp. $1-4$.

Norris, F. A. (1979). Handling, Storage and Grading of Oils and Oil Bearing Materials, In: Bailey's Industrial Oil and Fat Products, D. Swern, Editor, pp. 601-635, Interscience Publishers, New York. 
Plat, J. \& Mensink, R. P. (2005). Plant Stanol and Sterol Esters in the Control of Blood Cholesterol Levels: Mechanism and Safety Aspects. The American Journal of Cardiology. Vol. 96, No. 1, Supplement 1, pp. 15-22.

Quílez, J., García-Lorda, P., \& Salas-Salvado, J. (2003). Potential uses and benefits of phytosterols in diet: present situation and future directions. Clinical nutrition (Edinburgh, Scotland). Vol. 22, No. 4, pp. 343-351.

Ramamurthi, S., Bhirud, P. R., \& McCurdy, A. R. (1991). Enzymatic methylation of canola oil deodorizer distillate. JAOCS, Journal of the American Oil Chemists' Society. Vol. 68, No. (12), pp. 970-975.

Ramamurthi, S. \& McCurdy, A. (1993). Enzymatic pretreatment of deodorizer distillate for concentration of sterols and tocopherols. Journal of the American Oil Chemists' Society. Vol. 70, No. 3, pp. 287-295.

Rimm, E. B., Stampfer, M. J., Ascherio, A., Giovannucci, E., Colditz, G. A., \& Willett, W. C. (1993). Vitamin E Consumption and the Risk of Coronary Heart Disease in Men. New England Journal of Medicine. Vol. 328, No. 20, pp. 1450-1456.

Rohr, R. \& Trujillo-Quijano, J. A. (2002). Process for Extraction and Concentration of Liposoluble Vitamins, Growth Factors and Animal and Vegetable Hormones from Residues and By-products of Industrialized Animal and Vegetable Products. U.S. Patent No 6,344,573.

Rohr, R. \& Trujillo-Quijano, J. A. (2005). Process for separating unsaponifiable valuable products from raw materials. U.S. Patent No. 846941.

Rozner, S., Garti, N. (2006). The activity and absorption relationship of cholesterol and phytosterols. Colloids and Surfaces A: Physicochemical and Engineering Aspects Vol. No. pp. 435-456.

Sheabar, F. Z. \& Neeman, I. (1987). Concentration of tocopherols from soy oil deodorizer scum. La Rivista Italiana Delle Sostanze Grasse ZXZV. Vol. 2, No. pp. 19222.

Shimada, Y., Hirota, Y., Baba, T., Sugihara, A., Moriyama, S., Tominaga, Y., \& Terai, T. (1999). Enzymatic synthesis of steryl esters of polyunsaturated fatty acids. JAOCS, Journal of the American Oil Chemists' Society. Vol. 76, No. 6, pp. 713-716.

Shimada, Y., Nakai, S., Suenaga, M., Sugihara, A., Kitano, M., \& Tominaga, Y. (2000). Facile purification of tocopherols from soybean oil deodorizer distillate in high yield using lipase. JAOCS, Journal of the American Oil Chemists' Society. Vol. 77, No. 10, pp. 1009-1013.

Shishikura, A., Fujimoto, K., Kaneda, T., Arai, K., \& Saito, S. (1988). Concentration of Tocopherols from Soybean Sludge by Supercritical Fluid Extraction. J. Jpn. Oil Chem. Soc. Vol. 37, No. pp. 8-12.

Smet, P. (2008). Valorisatie van vetzuurdestillaten als biobrandstof door herverestering met glycerol. Master thesis: 1-68.

Smith Frank, E. (1967). Separation of tocopherols and sterols from deodorizer sludge and the like. U. S. Patent 3.335.154.

Strocchi, A. \& Marascio, G. (1993). Structural Modifications of 4,4'-Dimethyl Sterols during the Hydrogenation of Edible Vegetable Oils. Lipid / Fett. Vol. 95, No. 8, pp. 293299. 
Su-Min, J., Yong-Hun, P., Bong-Hyon, J., Hyon-Ho, S., \& Jong-Dok, S. (1992). Method of separation and concentration of sterol and tocopherol from distillated soybean powder. KR Patent No 9,205,695.

Sun, H., Wiesenborn, D., Tostenson, K., Gillespie, J., \& Rayas-Duarte, P. (1997). Fractionation of squalene from amaranth seed oil. Journal of the American Oil Chemists' Society. Vol. 74, No. 4, pp. 413-418.

Svensson, C. (1976). Use or disposal of by-products and spent material from the vegetable oil processing industry in Europe. Journal of the American Oil Chemists' Society. Vol. 53, No. 6, pp. 443-445.

Swern, D. (1986). Bailey's Industrial Oils and Fats. (John Wiley \& Sons, New York.

Szelag, H. \& Zwierzykowski, W. (1983). The Application of Molecular Distillation to Obtain High Concentration of Monoglycerides. Fette, Seifen, Anstrichmittel. Vol. 85, No. 11, pp. 443-446.

Takagi, Y. \& Kai, Y. (1984). Process for preparation of tocopherol concentrates. U.S. Patent 4454329.

Tangkam, K., Weber, N., \& Wiege, B. (2008). Solvent-free lipase-catalyzed preparation of diglycerides from co-products of vegetable oil refining. Grasas y Aceites. Vol. 59, No. 3, pp. 245-253.

Torres, C. F., Fornari, T., Torrelo, G., Señoráns, F. J., \& Reglero, G. (2009). Production of phytosterol esters from soybean oil deodorizer distillates. European Journal of Lipid Science and Technology. Vol. 111, No. 5, pp. 459-463.

Torres, C. F., Torrelo, G., Señorans, F. J., \& Reglero, G. (2007). A two steps enzymatic procedure to obtain sterol esters, tocopherols and fatty acid ethyl esters from soybean oil deodorizer distillate. Process Biochemistry. Vol. 42, No. 9, pp. 13351341.

Trautwein, E. A., Duchateau, G. S. M. J. E., Lin, Y., Mel'nikov, S. M., Molhuizen, H. O. F., \& Ntanios, F. Y. (2003). Proposed mechanisms of cholesterol-lowering action of plant sterols. European Journal of Lipid Science and Technology. Vol. 105, No. 3-4, pp. 171185.

Ubhayasekera, S. \& Dutta, P. (2009). Sterols and Oxidized Sterols in Feed Ingredients Obtained from Chemical and Physical Refining Processes of Fats and Oils. Journal of the American Oil Chemists' Society. Vol. 86, No. 6, pp. 595-604.

van Rensburg, S. J., Daniels, W. M. U., van Zyl, J. M., \& Taljaard, J. J. F. (2000). A Comparative Study of the Effects of Cholesterol, Beta-Sitosterol, Beta-Sitosterol Glucoside, Dehydro-epiandrosterone Sulphate and Melatonin on In Vitro Lipid Peroxidation. Metabolic Brain Disease. Vol. 15, No. 4, pp. 257-265.

Verhé, R., Van Hoed, V., Echim, C., Stevens, C., De Greyt, W., \& Kellens, M. (2008). Production of Biofuel from Lipids and Alternative Resources. (John Wiley \& Sons, Inc., 9780470385869)

Verleyen, T., Kamal-eldin, A., Dobarganes, C., Verhé, R., Dewettinck, K., \& Huyghebaert, A. (2001a). Modelling of alphatocopherol loss and oxidation products formed during thermoxidation in triolein and tripalmitin mixtures. Lipids in Health and Disease. Vol. 36, No. 7, pp. 719-726. 
Verleyen, T., Kamal-Eldin, A., Mozuraityte, R., Verhé, R., Dewettinck, K., Huyghebaert, A., \& De Greyt, W. (2002a). Oxidation at elevated temperatures: competition between a-tocopherol and unsaturated triacylglycerols. European Journal of Lipid Science and Technology. Vol. 104, No. 4, pp. 228-233.

Verleyen, T., Sosinska, U., Ioannidou, S., Verhe, R., Dewettinck, K., Huyghebaert, A., \& De Greyt, W. (2002b). Influence of the vegetable oil refining process on free and esterified sterols. Journal of the American Oil Chemists' Society. Vol. 79, No. 10, pp. 947-953.

Verleyen, T., Verhe, R., Cano, A., Huyghebaert, A., \& De Greyt, W. (2001b). Influence of triacylglycerol characteristics on the determination of free fatty acids in vegetable oils by Fourier transform infrared spectroscopy. J. Amer. Oil Chem. Soc. Vol. 78, No. 10, pp. 981-984.

Verleyen, T., Verhe, R., Garcia, L., Dewettinck, K., Huyghebaert, A., \& De Greyt, W. (2001c). Gas chromatographic characterization of vegetable oil deodorization distillate. Journal of Chromatography A. Vol. 921, No. 2, pp. 277-285.

Verleyen, T., Verhé, R., \& Kamal-eldin, A. (2003). Competitive oxidation between alfa tocopherol and unsaturated fatty acids under thermoxidation conditions. Lipid Oxidation Pathways. Vol. No. pp. 70-84.

Wang, H., Goto, M., Sasaki, M., \& Hirose, T. (2004). Separation of a-Tocopherol and Squalene by Pressure Swing Adsorption in Supercritical Carbon Dioxide. Industrial E Engineering Chemistry Research. Vol. 43, No. 11, pp. 2753-2758.

Wang, L., Du, W., Liu, D., Li, L., \& Dai, N. (2006). Lipase-catalyzed biodiesel production from soybean oil deodorizer distillate with absorbent present in tertbutanol system. Journal of Molecular Catalysis B: Enzymatic. Vol. 43, No. 1-4, pp. 29-32.

Warner, K. (2005). Effects on the Flavor and Oxidative Stability of Stripped Soybean and Sunflower Oils with Added Pure Tocopherols. Journal of Agricultural and Food Chemistry. Vol. 53, No. 26, pp. 9906-9910.

Watanabe, Y., Nagao, T., Hirota, Y., Kitano, M., \& Shimada, Y. (2004). Purification of tocopherols and phytosterols by a two-step in situ enzymatic reaction. JAOCS, Journal of the American Oil Chemists' Society. Vol. 81, No. 4, pp. 339-345.

Weber, N., Weitkamp, P., \& Mukherjee, K. D. (2001). Fatty acid steryl, stanyl, and steroid esters by esterification and transesterification in vacuo using Candida rugosa lipase as catalyst. Journal of Agricultural and Food Chemistry. Vol. 49, No. 1, pp. 6771.

Weber, N., Weitkamp, P., \& Mukherjee, K. D. (2002). Cholesterol-lowering food additives: Lipase-catalysed preparation of phytosterol and phytostanol esters. Food Research International. Vol. 35, No. 2-3, pp. 177-181.

Xu, Y., Shi, X., Du, X., Xing, M., Xu, T., Meng, J., \& Feng, Z. (2005). A method to extract natural vitamin $E$ from by-product of refined vegetable. CN Patent ZL 200510114851.X.

Yamada, Y., Shimizu, M., Sugiura, M., \& Yamada, N. (1999). Process for producing diglycerides. WO 1999/09119. 
Yang, H., Yan, F., Wu, D., Huo, M., Li, J., Cao, Y., \& Jiang, Y. (2009). Recovery of phytosterols from waste residue of soybean oil deodorizer distillate. Bioresource Technology. Vol. 101, No. 5, pp. 1471-1476.

Yong-Bo, H., Kim, N. H., Park, Y. H., Jong, B. H., Shin, H. H., \& Son, J. D. (1994). Method of Separation and Purification of Natural Tocopherol for Deodorized Sludge of Soybean oil. KR Patent No 9,402,715.

Zhao, Y., Sheng, G., \& Wang, D. (2000). Pilot-scale isolation of tocopherols and phytosterols from soybean sludge in a packed column using supercritical carbon dioxide, Proceedings of the Fifth International Symposium on Supercritical Fluids, Atlanta, Georgia, U.S.A. 


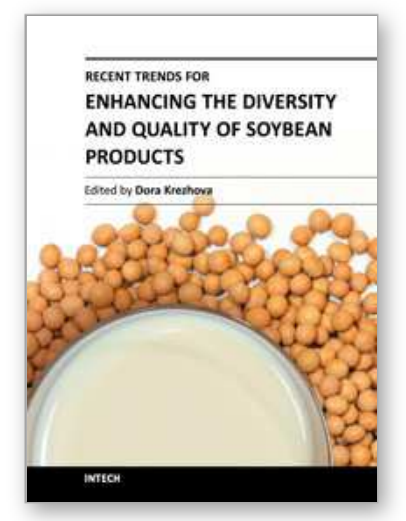

\author{
Recent Trends for Enhancing the Diversity and Quality of Soybean \\ Products \\ Edited by Prof. Dora Krezhova
}

ISBN 978-953-307-533-4

Hard cover, 536 pages

Publisher InTech

Published online 28, October, 2011

Published in print edition October, 2011

This book presents new aspects and technologies for the applicability of soybean and soybean products in industry (human food, livestock feed, oil and biodiesel production, textile, medicine) as well as for future uses of some soybean sub-products. The contributions are organized in two sections considering soybean in aspects of food, nutrition and health and modern processing technologies. Each of the sections covers a wide range of topics. The authors are from many countries all over the world and this clearly shows that the soybean research and applications are of global significance.

\title{
How to reference
}

In order to correctly reference this scholarly work, feel free to copy and paste the following:

Carlos F. Torres, Guzmán Torrelo and Guillermo Reglero (2011). Extraction and Enzymatic Modification of Functional Lipids from Soybean Oil Deodorizer Distillate, Recent Trends for Enhancing the Diversity and Quality of Soybean Products, Prof. Dora Krezhova (Ed.), ISBN: 978-953-307-533-4, InTech, Available from: http://www.intechopen.com/books/recent-trends-for-enhancing-the-diversity-and-quality-of-soybeanproducts/extraction-and-enzymatic-modification-of-functional-lipids-from-soybean-oil-deodorizer-distillate

\section{INTECH}

open science | open minds

\section{InTech Europe}

University Campus STeP Ri Slavka Krautzeka 83/A 51000 Rijeka, Croatia Phone: +385 (51) 770447 Fax: +385 (51) 686166 www.intechopen.com

\section{InTech China}

Unit 405, Office Block, Hotel Equatorial Shanghai No.65, Yan An Road (West), Shanghai, 200040, China 中国上海市延安西路65号上海国际贵都大饭店办公楼405单元 Phone: +86-21-62489820

Fax: +86-21-62489821 
(C) 2011 The Author(s). Licensee IntechOpen. This is an open access article distributed under the terms of the Creative Commons Attribution 3.0 License, which permits unrestricted use, distribution, and reproduction in any medium, provided the original work is properly cited. 